\title{
Propagation of short-period gravity waves at high-latitudes during the MaCWAVE winter campaign
}

\author{
K. Nielsen ${ }^{1}$, M. J. Taylor ${ }^{1}$, P.-D. Pautet ${ }^{1}$, D. C. Fritts ${ }^{2}$, N. Mitchell ${ }^{3}$, C. Beldon ${ }^{3}$, B. P. Williams ${ }^{2}$, W. Singer ${ }^{4}$, \\ F. J. Schmidlin ${ }^{5}$, and R. A. Goldberg ${ }^{6}$ \\ ${ }^{1}$ Center for Atmospheric and Space Sciences and Physics Department, Utah State University, Logan, UT 84322, USA \\ ${ }^{2}$ Colorado Research Associates, Northwest Research Associates, Boulder, CO 80301, USA \\ ${ }^{3}$ Department of Electronic and Electrical Engineering, University of Bath, UK \\ ${ }^{4}$ Leibniz-Institut für Atmosphärenphysik, Kühlungsborn, Germany \\ ${ }^{5}$ NASA/Goddard Space Flight Center, Wallops Flight Facility, Code 972, Wallops Island, VA 23337, USA \\ ${ }^{6}$ NASA/Goddard Space Flight Center, Code 612.3, Greenbelt, MD 20771, USA
}

Received: 14 October 2005 - Revised: 13 March 2006 - Accepted: 10 May 2006 - Published: 3 July 2006

Part of Special Issue "MaCWAVE: a rocket-lidar-radar program to study the polar mesosphere during summer and winter"

\begin{abstract}
As part of the MaCWAVE (Mountain and Convective Waves Ascending Vertically) winter campaign an allsky monochromatic CCD imager has been used to investigate the properties of short-period mesospheric gravity waves at high northern latitudes. Sequential measurements of several nightglow emissions were made from Esrange, Sweden, during a limited period from 27-31 January 2003. Coincident wind measurements over the altitude range $(\sim 80-100 \mathrm{~km})$ using two meteor radar systems located at Esrange and Andenes have been used to perform a novel investigation of the intrinsic properties of five distinct wave events observed during this period. Additional lidar and MSIS model temperature data have been used to investigate their nature (i.e. freely propagating or ducted). Four of these extensive wave events were found to be freely propagating with potential source regions to the north of Scandinavia. No evidence was found for strong orographic forcing by short-period waves in the airglow emission layers. The fifth event was most unusual exhibiting an extensive, but much smaller and variable wavelength pattern that appeared to be embedded in the background wind field. Coincident wind measurements indicated the presence of a strong shear suggesting this event was probably due to a large-scale Kelvin-Helmholtz instability.
\end{abstract}

Keywords. Atmospheric composition and structure (Airglow and aurora) - Meteorology and atmospheric dynamics (Middle atmospheric dynamics; Waves and tides)

Correspondence to: K. Nielsen

(knielsen@cc.usu.edu)

\section{Introduction}

The MaCWAVE (Mountain and Convective Waves Ascending Vertically) program was designed to investigate the influence of gravity waves of various scale sizes on the highlatitude Mesosphere and Lower Thermosphere (MLT) region (altitude $\sim 80$ to $100 \mathrm{~km}$ ). Two intensive campaigns were conducted from northern Scandinavia using a variety of ground based radar, optical and in-situ rocket borne measurements centered on two key sites: Andenes, Norway $\left(69.3^{\circ} \mathrm{N}, 16.0^{\circ} \mathrm{E}\right)$, summer 2002 and Esrange, Sweden $\left(67.9^{\circ} \mathrm{N}, 21.1^{\circ} \mathrm{E}\right)$ during January 2003 . The Norwegian measurements were conducted during July 2002 and focused primarily on wave activity in the vicinity of the cold summertime mesopause. In contrast, Esrange, Sweden was the focus of the winter-time mountain wave measurements with two main rocket salvos during January 2003. In each campaign the key goals were to quantify the seasonal effects of differing gravity wave forcing of the MLT region (Goldberg et al., 2006).

In particular, the winter-time measurements were designed to measure the structure and propagation of orographically generated waves due to expected strong eastward wind flow over the Scandinavian mountain range that separates the two main sites. The primary goal was to track the mountain waves from their lower altitude source region up into the MLT where they were expected to create instabilities and significant wave-mean flow interactions. Previous studies using balloon and airborne measurements have revealed that northern Scandinavia is a very active winter-time site for the penetration of mountain waves into the MLT region with the waves often reaching large amplitudes (Bacmeister et al.,

Published by Copernicus GmbH on behalf of the European Geosciences Union. 
1994). Significant mountain wave activity was detected during the campaign using rocket-borne falling spheres wind and temperature data (Wang et al., 2006). However, a sudden stratospheric warming occurred on 18 January, shortly before the main sequence of measurements began, which significantly altered the mean wind field around the $50 \mathrm{~km}$ level (Blum et al., 2006), including a shear in the zonal mean flow, that acted to block the upward penetration of mountain waves into the mesosphere. Although this shear prevented further upward penetration of mountain waves (which exhibit zero or very low phase speeds), our measurements show that it did not impede gravity waves of other origins with significantly higher phase speeds and/or different propagation directions from reaching the MLT region.

The winter time program employed a broad range of coordinated measurements from both sites including radars, lidars, and balloons to fully characterize the upstream and downstream tropospheric/stratospheric wind conditions as well as the mesospheric response primarily to gravity waves and tidal activity. As part of this program an all-sky monochromatic imaging system was deployed at Esrange to investigate short-period gravity wave activity using high resolution, sequential measurements of several nightglow emission layers occuring in the MLT region $(\sim 80-100 \mathrm{~km})$. Allsky imagers have been shown to be very effective at characterizing the scale-sizes and motions of geographically extensive, short-period $(<1 \mathrm{~h})$ waves exhibiting vertical wavelengths $>10 \mathrm{~km}$ (i.e. significantly larger than the airglow emission layer depths). Measurements have been primarily made at mid- and low latitudes and have revealed a rich spectrum of waves (Swenson and Mende, 1994; Taylor et al., 1995b; Wu and Killeen, 1996; Taylor et al., 1997; Nakamura et al., 1999; Walterscheid et al., 1999; Smith et al., 2000; Hecht et al., 2001a,b; Ejiri et al., 2003; Medeiros et al., 2003; Nakamura et al., 2003; Brown et al., 2004; Pautet et al., 2005). These waves usually exhibit relatively high phase speeds (typically a few ten's of meters per second) and are able to penetrate rapidly (few hours) from their tropospheric source regions into the MLT where they saturate and break, depositing significant amounts of momentum (Fritts and Alexander, 2003, and references therein). Indeed, it has been shown that as much as $\sim 70 \%$ of the momentum transported into the MLT region is by short-period gravity waves (Fritts and Vincent, 1987). The culminating effect of this momentum deposition contributes significantly towards the closure of the mesospheric jets and the formation of the cold summer mesopause phenomena (e.g. Dunkerton, 1982; Holton, 1982; Nastrom et al., 1982; Garcia and Solomon, 1985; Fritts and Yuan, 1989a; Garcia, 1989).

Our initial goal was to search for mountain wave signatures in the MLT emissions. However, in the absence of such wave forcings we have focused on characterizing the waves that were present during this period. In particular, we have used coincident meteor radar wind measurements available from both sites, lidar temperature data, and falling sphere wind data to investigate the intrinsic properties of the wave events and to assess their propagation characteristics (i.e. freely propagating or ducted).

Optical observations of short-period gravity waves at high northern latitudes are relatively few, due to frequent "contamination" of the faint airglow data by strong auroral emissions (Clairemidi et al., 1985; Taylor and Henriksen, 1989). However, several well-defined, short-period wave events were measured primarily in the near infrared $\mathrm{OH}$ emission (peak altitude $\sim 87 \mathrm{~km}$ ) and the $\mathrm{Na}$ emission (peak $\sim 90 \mathrm{~km}$ ) with supporting data from the $\mathrm{O}_{2}(0,1)$ band (peak $\sim 94 \mathrm{~km}$ ). In each case the wave forms were found to be freely propagating throughout the MLT region. Previous measurements at lower latitudes appear to show a preponderance for ducted wave motion (Isler et al., 1997; Walterscheid et al., 1999; Hecht et al., 2001a,b; Pautet et al., 2005). As far as we are aware these are the first clear measurements establishing freely propagating wave motions at high latitude. These (limited) measurements highlight the importance for further coordinated wind, temperature, and wave studies to assess their nature and associated influence on the high latitude MLT dynamics via momentum deposition.

\section{Instrumentation}

As part of the winter time MaCWAVE program, Utah State University (USU) deployed a monochromatic all-sky system at the European Esrange Facility in northern Sweden to investigate short-period gravity wave and their characteristics in the MLT region. This is a well-proven, compact field instrument that has been used on several previous campaigns to study gravity waves over an exceptionally large field of view $\sim 5 \times 10^{5} \mathrm{~km}^{2}$. The imaging system consisted of a photometrics $\mathrm{CH} 250$ camera head fitted with a $1024 \times 1024$ pixel back illuminated bare CCD (of high quantum efficiency $50-80 \%$ ), an all-sky telecentric lens system and a computer controlled filter wheel, enabling sequential observations of several different airglow emissions with a cadence of several minutes. The data were $2 \times 2$ binned on chip to $512 \times 512$ pixels providing a spatial zenith resolution of approximately $0.6 \mathrm{~km}$.

For this campaign five filters were used to investigate the following MLT emissions: the NIR broadband $(715-930 \mathrm{~nm})$ $\mathrm{OH}$ emission and the $\mathrm{O}_{2}(0,1)$ band at $865.5 \mathrm{~nm}$, the $\mathrm{Na}$ $(589.2 \mathrm{~nm})$ doublet, and the OI $(557.7 \mathrm{~nm})$ "green line" emission. In addition, measurements of the background sky (Bg) were made at $572.5 \mathrm{~nm}$ to monitor cloud coverage and to provide a background measure for the narrow band filters. The NIR OH filter incorporated a notch at $\sim 865 \mathrm{~nm}$ to limit contributions from the $\mathrm{O}_{2}(0,1)$ band. Further details of this imaging system and the filter specifications are given in Taylor et al. (1995b).

For this investigation we have utilized wind data primarily from two meteor radar systems. One radar was located at Andenes, Norway and operated by the Leibniz institute, 
Germany while the other radar was sited at the Esrange facility, Sweden operated by the University of Bath, UK. Both of these radar systems are commercially produced all-sky VHF system manufactured under the brand name of SkiYmet (Hocking et al., 2001). Each radar utilized crossed antenna elements on transmission and reception to ensure a near uniform azimuthal sensitivity to meteor echoes in the altitude range $80-110 \mathrm{~km}$. Each system also used a 5-antenna interferometer for signal reception resulting in a range accuracy of $2 \mathrm{~km}$ and an angular accuracy of about $2^{\circ}$ in meteor location. The Andenes radar used a $12-\mathrm{kW}$ peak transmission power, a pulse width of $13 \mu$ s and operated at a frequency of 32.55 MHz. The Esrange system used a transmitter of $6-\mathrm{kW}$ peak power and operated with a duty cycle of $15 \%$ at a frequency of $32.5 \mathrm{MHz}$. Both radars used a pulse repetition rate of $2144 \mathrm{MHz}$. Continuous wind measurements have been obtained at Esrange since August 1999 and at Andenes since October 2001 (Mitchell et al., 2002; Singer et al., 2004).

In addition, available temperature data on 27/28 January obtained by the Weber Na lidar operated at ALOMAR near Andenes, Norway have been used. Details of the the system are described in She et al. (2002). For this campaign the lidar transmitted three frequencies to measure the Doppler shift and broadening of the sodium $D_{2}$ line to infer temperature from $\sim 80$ to $105 \mathrm{~km}$ altitude. The data have been analyzed to give temperature profiles at $15 \mathrm{~min}$ (temporal) and $1 \mathrm{~km}$ (vertical) resolution using two beams inclined at $20^{\circ}$ west and east of zenith. Further details of the lidar measurements during the campaign can be found in Williams et al. (2006).

\section{Observations and analysis}

Figure 1 shows a map of northern Scandinavia indicating the two key observation sites at Andenes and Esrange which are separated by $\sim 250 \mathrm{~km}$. The circles indicates regions in which the majority of meteors are detected for each of the radars ( $\sim 400 \mathrm{~km}$ diameter at MLT heights). The large circle indicates the nominal field of view ( $\sim 300 \mathrm{~km}$ radius) of the all-sky imager at $90 \mathrm{~km}$ altitude which essentially encompasses both radar observing volumes.

The imager was operated for a total of nine nights during the moon-down period from 22-31 January during the main MaCWAVE observation period (Goldberg et al. (2006)). Several short-period gravity wave events were measured on three nights $(27 / 28,29 / 30$, and 30/31 January). For the remaining six nights, the observations were compromised by moonlight, cloud cover, and strong auroral activity. The nominal observing sequence was $\left[\mathrm{OH}-\mathrm{O}_{2}-\mathrm{OH}-\mathrm{Na}-\mathrm{OH}-\mathrm{Bg}\right]$ with a cadence time of $\sim 6 \mathrm{~min}$. Integration times ranged from $15 \mathrm{~s}$ for the bright $\mathrm{OH}$ emission to $90 \mathrm{~s}$ for the $\mathrm{O}_{2}$ emission, and $120 \mathrm{~s}$ for the fainter $\mathrm{Na}$ emission. Due to the frequent presence of aurora the OI $(557.7 \mathrm{~nm})$ observations were only attempted on the night of 27/28 January.

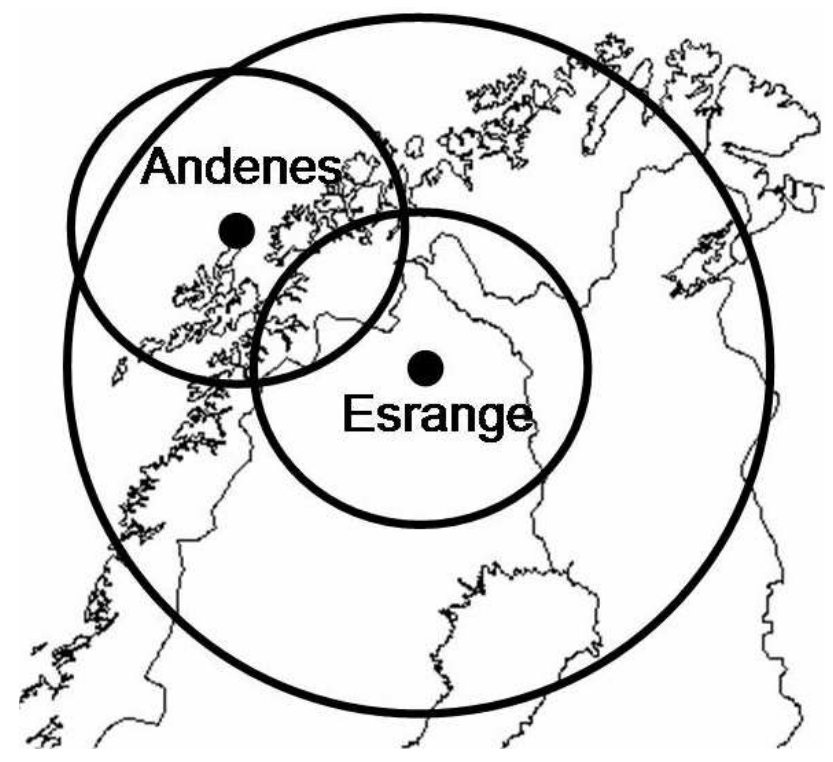

Fig. 1. Map showing northern Scandinavia and the two observation sites (black dots). The nominal circular field of view $(\sim 600 \mathrm{~km}$ at $90-\mathrm{km}$ altitude) of the airglow imager is also marked. The two smaller circles show the regions where the majority of meteor echoes are detected by the two meteor radars (diameter of $\sim 400 \mathrm{~km}$ ).

Figure 2 shows four example images of two gravity wave events imaged in each of the four airglow emissions on 27/28 January. The $\mathrm{O}_{2}$ and $\mathrm{OH}$ data were obtained at similar times ( 16:18 UT) showing an extensive band-type event in the lower half of the image (e.g.Taylor et al. (1997)). The OI and $\mathrm{Na}$ image pair were obtained 15-20 min later and illustrate the propagation of the wave pattern through the field of view. A second wave event is also evident in these images entering the field of view from the right side. Similar morphology wave patterns associated with short-period gravity wave propagating through the MLT region have been reported from numerous sites at mid- and low latitudes (Swenson and Mende, 1994; Taylor et al., 1995b; Wu and Killeen, 1996; Taylor et al., 1997; Nakamura et al., 1999; Walterscheid et al., 1999; Smith et al., 2000; Hecht et al., 2001b; Medeiros et al., 2003; Nakamura et al., 2003; Ejiri et al., 2003; Brown et al., 2004; Pautet et al., 2005). Also evident in the bottom left of the Na image is a Super Loki falling sphere launch providing wind profile measurements in addition to the dual meteor MLT radar data measurements.

The image data have been analyzed to map each wave event and to determine their characteristics (horizontal wavelength and direction of motion, observed phase speed and wave periodicity). The geographical analysis was performed using standard image data processing techniques which utilized the star field to accurately orient and scale the raw image data (Garcia et al., 1997). The stars were then removed from each image and the data were mapped onto 


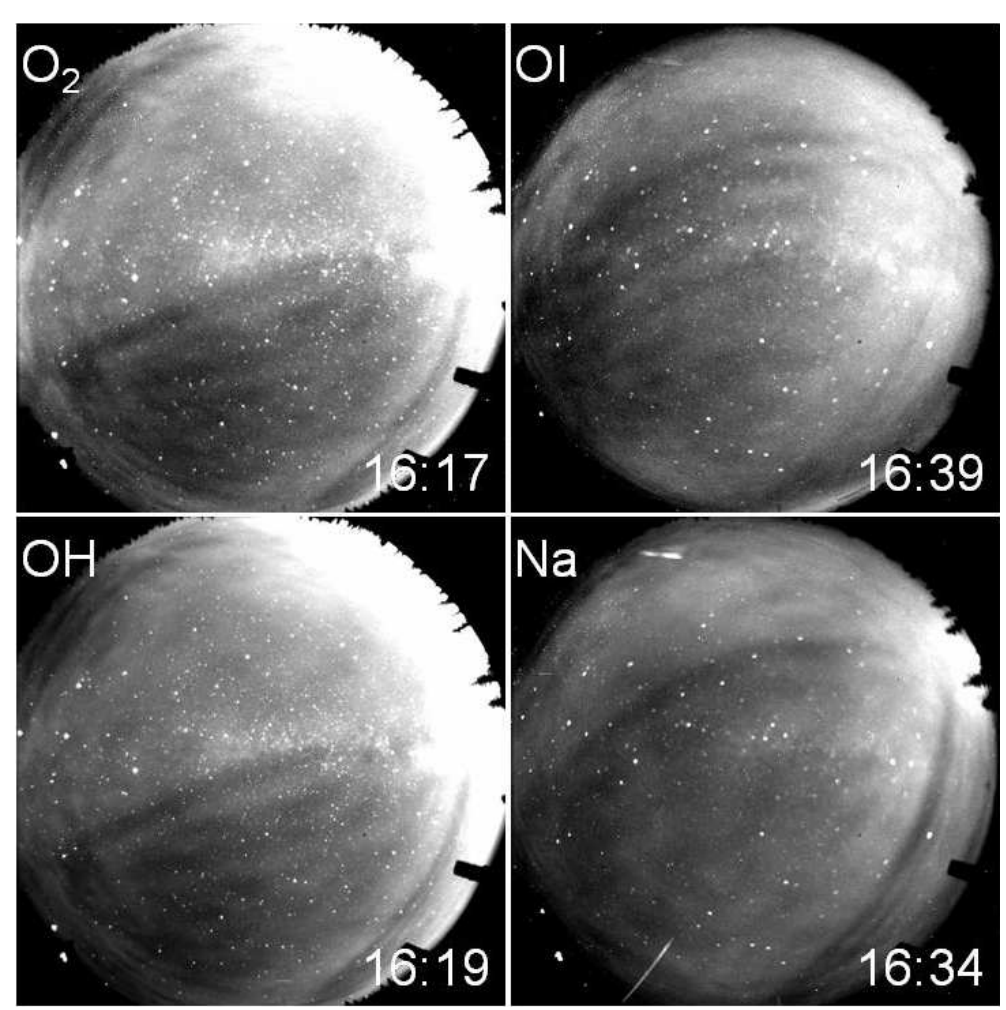

Fig. 2. Example all-sky images recorded in the $\mathrm{OI}, \mathrm{O}_{2}, \mathrm{Na}$, and $\mathrm{OH}$ emissions on $27 / 28$ January. The two images to the left are taken near simultaneously and show a wave propagating across the field from the lower right towards the upper left in the $\mathrm{OH}_{\text {and }} \mathrm{O}_{2}$ emissions . Another wave entering the field of view is barely visible to the lower right. The right panels show the same waves at a later time in the $\mathrm{Na}$ and OI emissions. The progression of the waves are evident. Also seen in the Na emission is a Super Loki rocket just after launch. The displayed times are in UT.

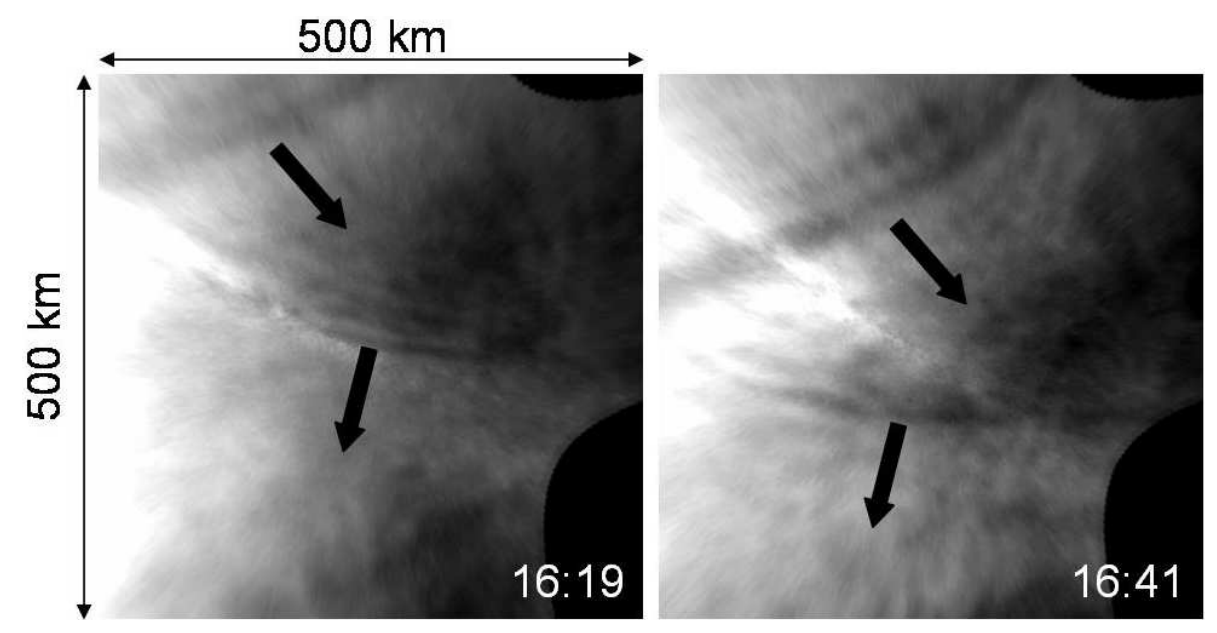

Fig. 3. Examples of fully processed images in the $\mathrm{OH}$ emission at two different times on the night of 27 January. The images were unwarped onto a $500 \times 500 \mathrm{~km}$ geographic grid. The two wave events observed on this night are present in both images and their motions are indicated by the arrows. 
a $500 \times 500 \mathrm{~km}$ geographic grid assuming nominal emission layer heights of $87 \mathrm{~km}(\mathrm{OH}), 90 \mathrm{~km}(\mathrm{Na}), 94 \mathrm{~km}\left(\mathrm{O}_{2}\right)$, and $96 \mathrm{~km}$ (OI) (Garcia et al., 1997; Pautet et al., 2005). Figure 3 shows two $\mathrm{OH}$ images processed in this manner illustrating the two wave events observed on 27/28 January and described in Fig. 2. The processed images are separated by $\sim 22 \mathrm{~min}$ and clearly show the motion of the two wave events. The horizontal parameters were then determined using well-developed 2-D Fourier analysis techniques as described in Taylor and Garcia (1995a), Gardner et al. (1996), Garcia et al. (1997), and Coble et al. (1998), together with time series analysis of their motions.

Finally, maps of the individual wave events were used to study their morphology, geographical extent, location and motion with respect to the meteor radar sites. Figure 4 shows the location and orientation of the most prominent wave crests evident at 16:41 UT (see Fig. 3). The map clearly shows that the two events have quite different horizontal wavelengths. The smaller scale event (wave 1) was observed in the vicinity of Esrange and Alomar and propagating towards the $\sim \mathrm{S}-\mathrm{SW}$ while the larger scale event (wave 2) progressed over Andenes towards $\sim \mathrm{SE}$. This event was later observed directly overhead at Esrange at $\sim 17: 50$ UT (discussed later in Sect. 4).

Both meteor radar data sets have been processed to determine the zonal and meridional winds over the altitude range $80-100 \mathrm{~km}$. The Esrange meteor echoes were separated into six height gates centered at 81.1, 84.6, 87.5, 93.3, and $96.8 \mathrm{~km}$ with widths of 5, 3, 3, and $5 \mathrm{~km}$, respectively. The zonal and meridional winds in each height range were then determined using a 2-h window incremented in 1-h intervals resulting in a time series of hourly averaged horizontal winds. Figure 5 shows the zonal and meridional winds from the period of 24 January to 1 February as determined by the Esrange meteor radar. The data are dominated by a strong semi-diurnal tidal motion during this period (Goldberg et al., 2006). The Andenes horizontal wind field was analyzed in a similar manner, but using slightly different time-height bins of $1 \mathrm{~h} \times 3 \mathrm{~km}$ over the altitude range $80-100 \mathrm{~km}$ yielding time series for the zonal and meridional winds centered at six altitudes at $82,85,88,91,94$, and $98 \mathrm{~km}$.

In addition to this standard output, the Esrange wind data were also re-analyzed to provide higher time-resolution data by averaging the data over 4 altitudes each centered at the nominal airglow emission layer heights $(87,90$, and $94 \mathrm{~km}$ for the $\mathrm{OH}, \mathrm{Na}$, and $\mathrm{O}_{2}$, respectively). Due to the increased number of meteor counts within these broader height range gates $(8 \mathrm{~km})$ we were able to increase the time resolution significantly to 12 -min using a 24-min sliding window. Further details concerning the SKiYMET radar data analysis methods are given in Hocking et al. (2001), Mitchell et al. (2002), and Singer et al. (2004).

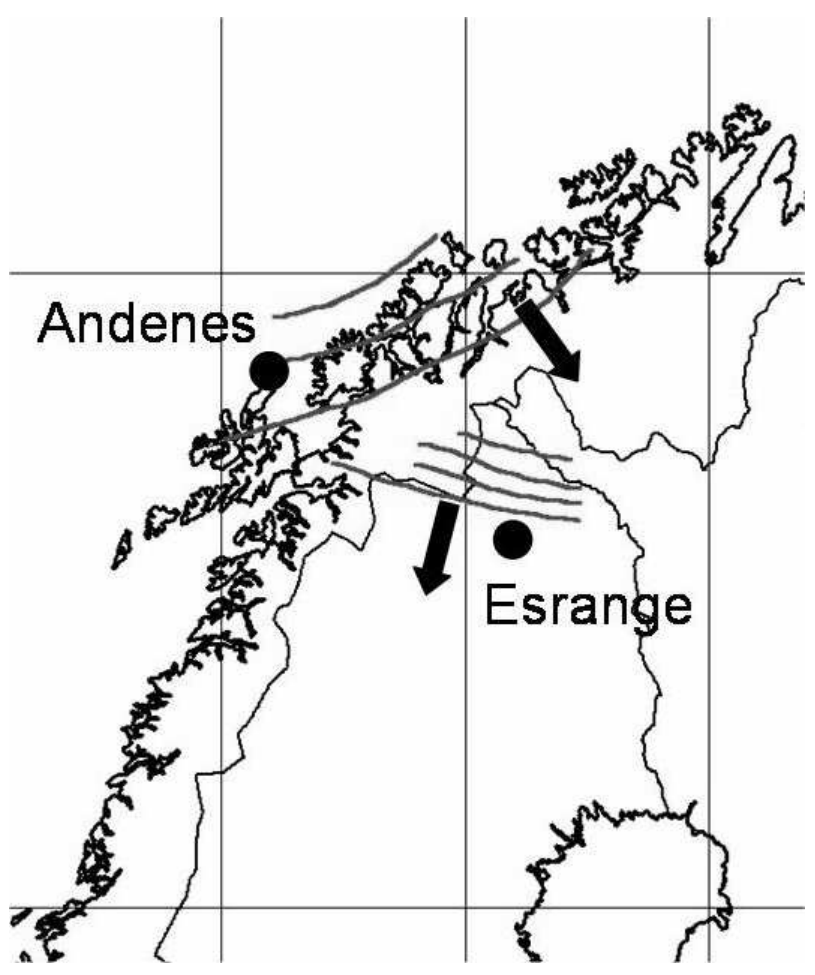

Fig. 4. Geographic map showing northern Scandinavia and the two observation sites participating in the campaign. Projected onto the map are the two waves observed on the night of 27/28 January (at 16:41 UT) and their respective direction of propagation. Wave 1 propagated towards S-SW and is moving across the Esrange meteor radar field of view. In contrast, wave 2 initially progressed overhead Andenes on a SE heading towards Esrange.

\section{Results}

Due to the frequent presence of clouds and aurora the available time for high quality observations of the much fainter airglow emissions was limited to $\sim 15 \mathrm{~h}$. Nevertheless, five well-defined short-period wave events were observed during three nights: 27/28, 29/30, and 30/31 January. Coincident mesospheric gravity wave and wind measurements are relatively rare, especially at high latitudes, and here we utilize these data to perform case studies of each of these wave events.

\section{$4.127 / 28$ January}

Observations on this night commenced at 16:00 UT (17:00 LT around nautical twilight) and lasted for $13 \mathrm{~h}$ (until 05:00 UT) on the 28 January. The sky remained clear with auroral activity commencing around 20:50 UT. Two distinct short-period wave events were imaged immediately and were observed to extend over much of the imagers field of view as they each progressed uniformly across the sky (see Figs. 2 and 3). The smaller scale event (wave 1) was observed for 

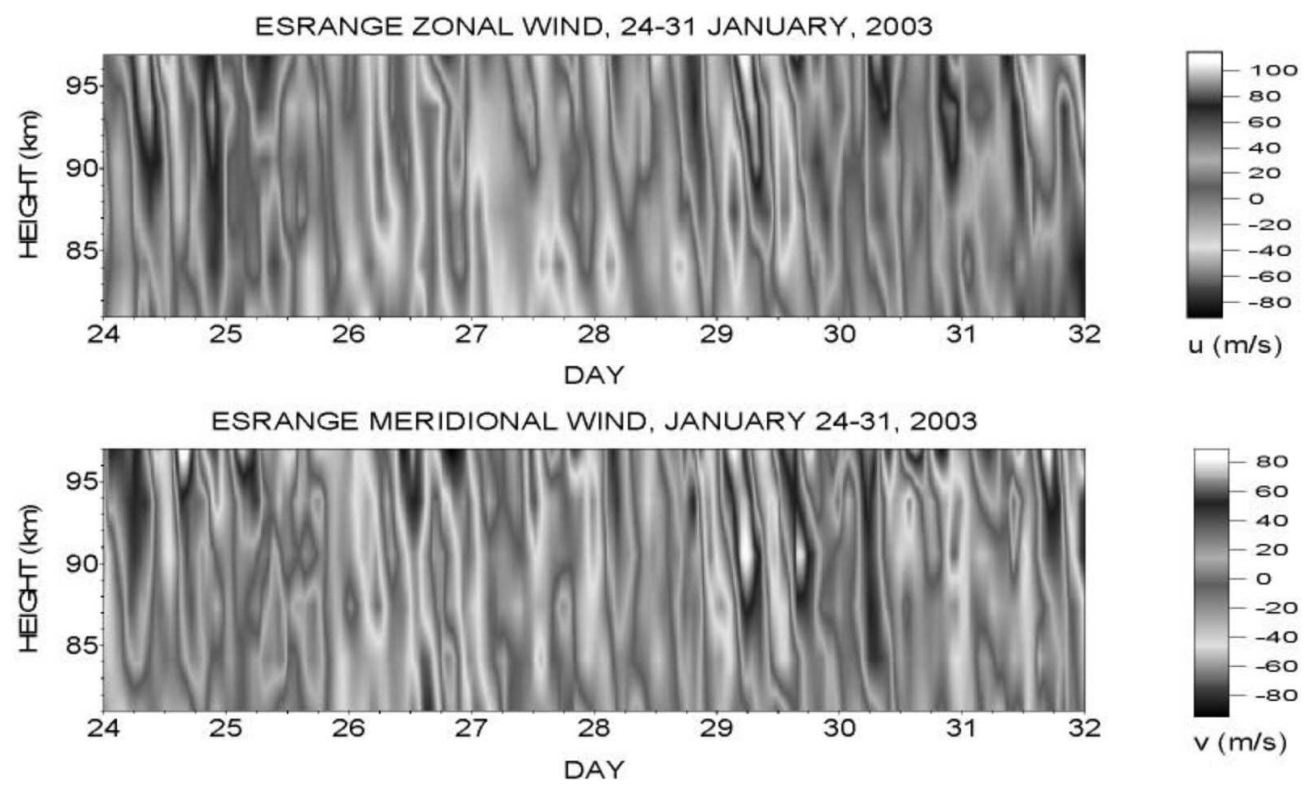

Fig. 5. Contour plot of the zonal and meridional winds measured by the Esrange meteor radar from 24 January to 1 February. A strong semi-diurnal tide was present during the campaign.

Table 1. Summary of average observed and derived intrinsic wave parameters.

\begin{tabular}{lllllllll}
\hline Date & Time (UT) & Emission & $\begin{array}{l}\text { Wavelength } \\
(\mathrm{km}) \pm 1 \mathrm{~km}\end{array}$ & $\begin{array}{l}\text { Direction } \\
\pm 5^{\circ}\end{array}$ & $\begin{array}{l}\text { Phase Speed } \\
(\mathrm{m} / \mathrm{s}) \pm 5 \mathrm{~m} / \mathrm{s}\end{array}$ & $\begin{array}{l}\text { Period } \\
(\mathrm{min})\end{array}$ & $\begin{array}{l}\mathrm{c}_{i}(\mathrm{~m} / \mathrm{s}) \\
\pm 6 \mathrm{~m} / \mathrm{s}\end{array}$ & $\mathrm{T}_{i}$ (min) \\
\hline 27 Jan & $16: 00-17: 20$ & $\mathrm{OH}$ & 26 & 185 & 49 & $9 \pm 1$ & 55 & $8 \pm 1$ \\
& & $\mathrm{Na}$ & 28 & 186 & 54 & $9 \pm 1$ & 48 & $10 \pm 2$ \\
& & $\mathrm{O}_{2}$ & 27 & 186 & 41 & $11 \pm 2$ & 19 & $24 \pm 8$ \\
27 Jan & $16: 00-19: 40$ & $\mathrm{OH}$ & 41 & 145 & 61 & $11 \pm 1$ & 80 & $9 \pm 1$ \\
& & $\mathrm{Na}$ & 42 & 139 & 46 & $15 \pm 2$ & 54 & $13 \pm 2$ \\
29 Jan & $21: 20-23: 30$ & $\mathrm{Na}$ & 28 & 233 & 29 & $16 \pm 3$ & 64 & $7 \pm 1$ \\
30 Jan & $20: 50-21: 40$ & $\mathrm{OH}$ & 29 & 157 & 72 & $7 \pm 1$ & 27 & $18 \pm 4$ \\
30 Jan & $22: 10-23: 40$ & $\mathrm{OH}$ & 14 & 140 & 61 & $4 \pm 1$ & 0 & - \\
& & $\mathrm{Na}$ & 10 & 142 & $\dagger$ & - & - & - \\
\hline
\end{tabular}

$\dagger \mathrm{Na}$ speed indeterminate due to low sample rate

$\sim 1.5 \mathrm{~h}$ before it progressed outside the field of view while the larger scale event (wave 2) was observed for $\sim 4 \mathrm{~h}$. Both waves were detected in all four airglow emissions (including the OI $557.7 \mathrm{~nm}$ emission). However, even faint auroral activity significantly restricted the spectral analysis of the OI data and they were curtailed on subsequent nights. Both wave events were somewhat unusual in their morphology as in each emission they were characterized by a dark leading edge followed by several trailing wave crests moving into a comparatively bright featureless region. By 20:00 UT both events were only evident at low elevations and auroral emissions then obscured further observations on this night.
Table 1 lists the measured horizontal wavelength, observed phase speed and direction of motion of these two wave events in the $\mathrm{OH}, \mathrm{Na}$, and $\mathrm{O}_{2}$ emissions. (Auroral activity restricted the spectral analysis of the OI data). In each emission the horizontal wavelength was found to be $\sim 27 \mathrm{~km}$ (with an uncertainty of $\pm 1 \mathrm{~km}$ ). The observed phase speeds varied from $\sim 40$ to $55 \mathrm{~m} / \mathrm{s}$ with an uncertainty of $\pm 5 \mathrm{~m} / \mathrm{s}$ yielding an observed periodicity of $10 \pm 1 \mathrm{~min}$. The direction of wave propagation was $185 \pm 5^{\circ}$ as measured clockwise from north. In comparison wave 2 exhibited a significantly larger horizontal wavelength of $\sim 42 \mathrm{~km}$, but a similar magnitude phase speed $(\sim 50-60 \mathrm{~m} / \mathrm{s})$ and an observed period ranging from 11-15 min. This event progressed towards the SE on a heading of $\sim 140 \pm 5^{\circ}$. 


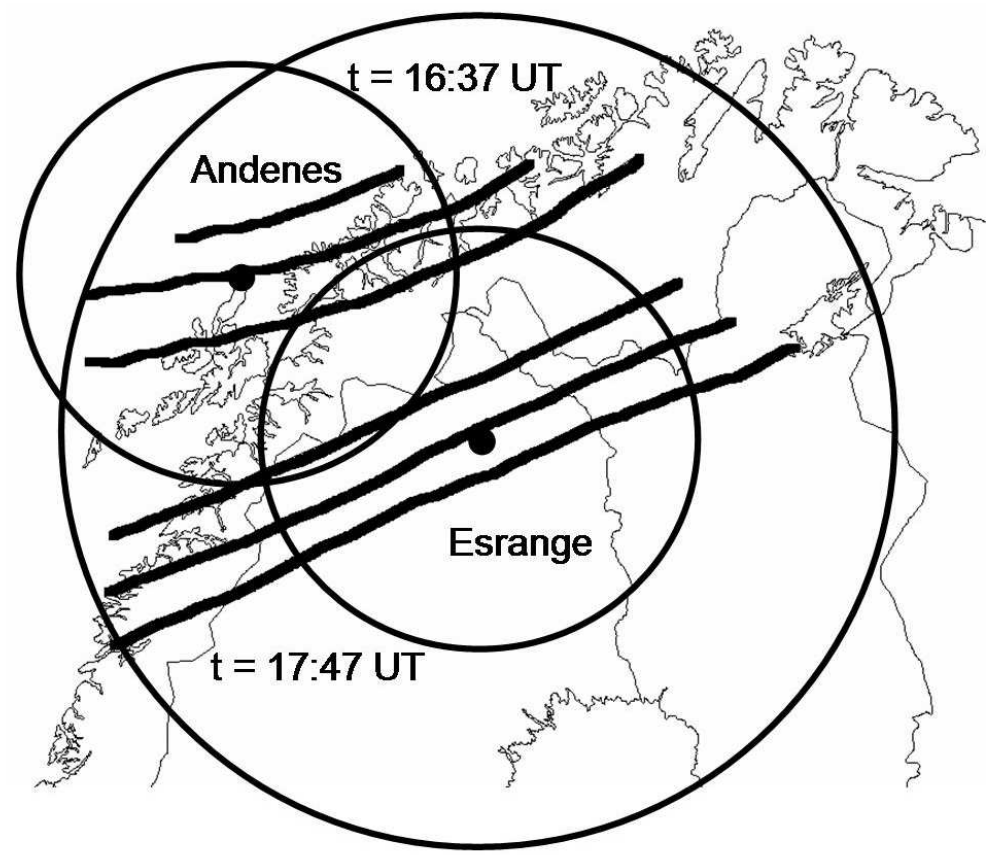

Fig. 6. Geographic projection of wave 2 observed on 27/28 January at 16:37 UT and 17:47 UT. As the wave progressed over both meteor radars the data are ideal for comparison of the intrinsic wave parameters derived from both wind data sets.

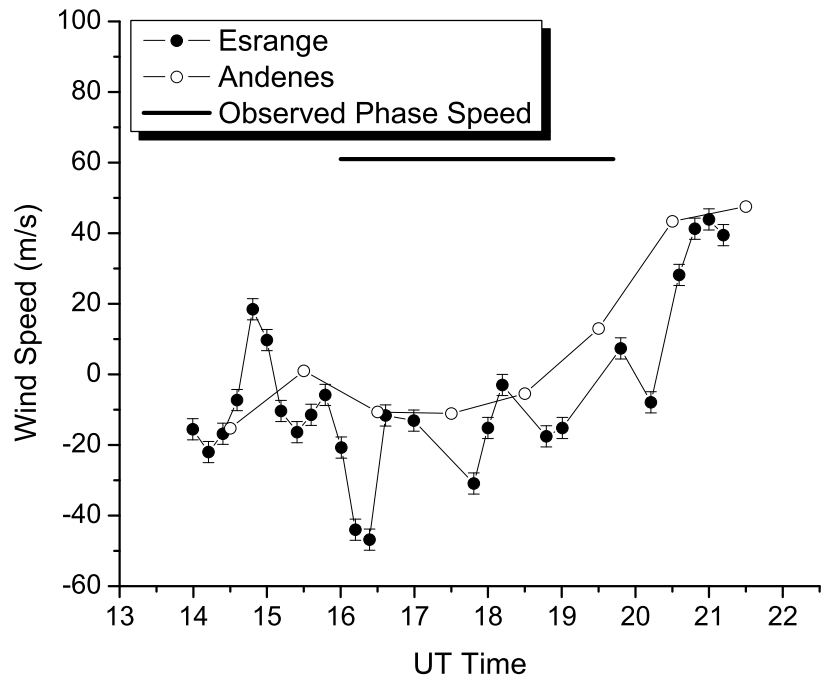

Fig. 7. Graph showing the horizontal wind in the direction of motion of wave 2 (observed on 27/28 January) using the two meteor radar data sets. The Esrange data are 12-min averages (error bars are $\pm 3 \mathrm{~m} / \mathrm{s}$ ), while the Andenes data are hourly averages. The horizontal bar indicates the phase speed and period of observation of wave 2 .

Figure 6 shows a composite map of this wave event imaged in the $\mathrm{OH}$ emission at two instances as it progressed initially overhead at Andenes (at 16:37 UT) and 70 min later when it was observed overhead at Esrange (consistent with a
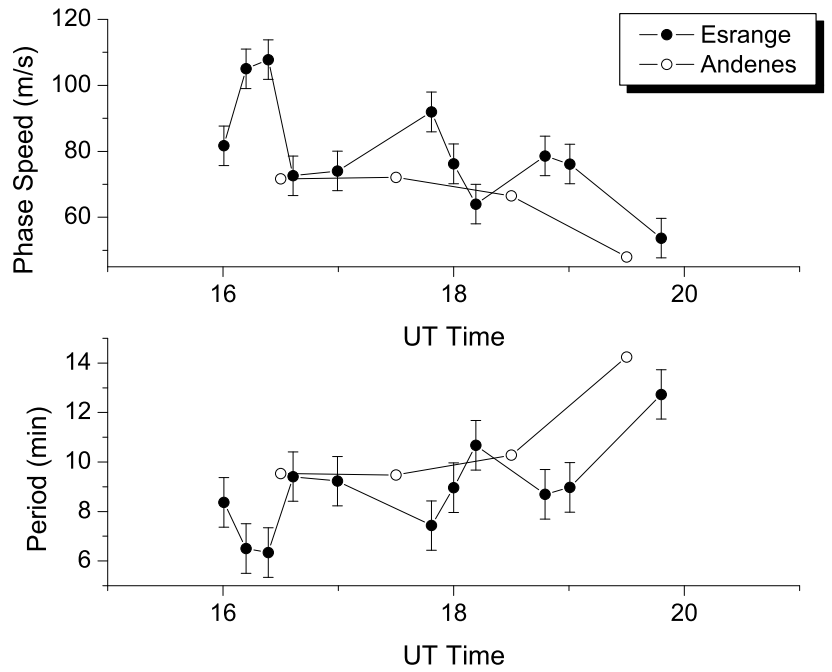

Fig. 8. Plot showing the derived intrinsic parameters for wave 2 using the Esrange and Andenes meteor wind data on 27/28 January. The top panel shows the intrinsic phase speed whereas the bottom panel plots the intrinsic period. Both the intrinsic phase speed and intrinsic period exhibit similar trends for the two stations. The estimated error in the intrinsic phase speed is $\pm 6 \mathrm{~m} / \mathrm{s}$, and $\pm 1 \mathrm{~min}$ for the intrinsic period.

uniform observed phase speed of $\sim 50-60 \mathrm{~m} / \mathrm{s}$ ). In each case the three solid lines indicate the location of the leading edge of the dark band and the adjacent dark wave forms. As this 

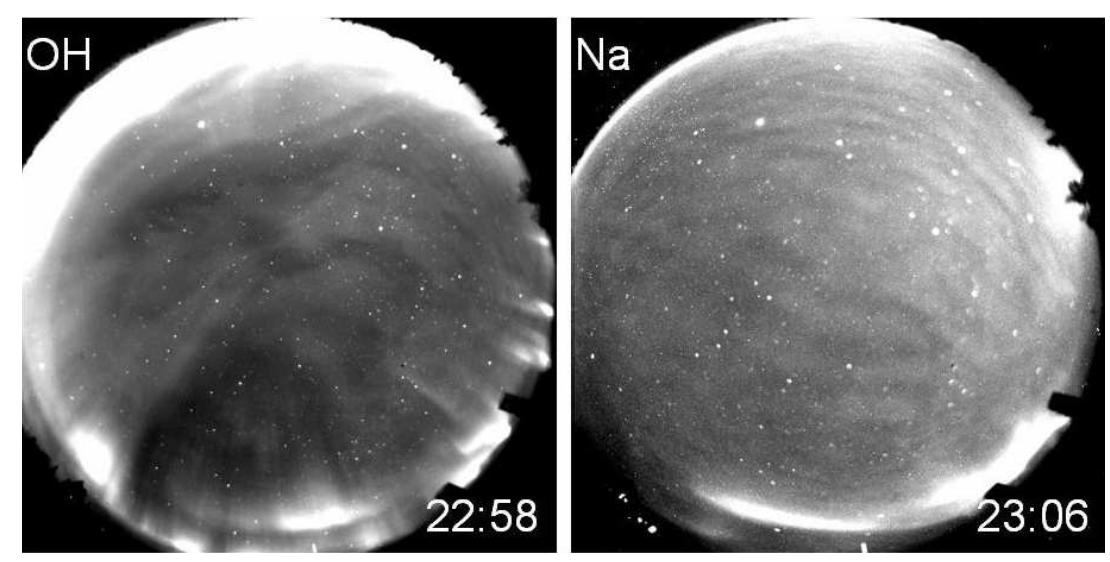

Fig. 9. Two raw all-sky images illustrating the difficulty of observing airglow emissions at high latitude with auroral emissions present. The $\mathrm{OH}$ image (left) shows auroral features covering the majority of the field of view. The Na image (right) was obtained 8 min later and an extensive gravity wave is clearly evident.

wave event passed overhead at both radar sites the data are ideally suited for an investigation of the temporal and spatial properties of its intrinsic wave parameters using the wind data from both sites.

Figure 7 plots the magnitude of the wind speed versus time in the direction of motion of wave 2 as derived separately from both radar data sets. The Andenes data are shown in one-hour intervals centered at $88 \mathrm{~km}$ and averaged over a $3 \mathrm{~km}$ height range while the Esrange data are plotted at a higher temporal resolution of $12 \mathrm{~min}$ centered at the nominal $\mathrm{OH}$ emission altitude $(87 \mathrm{~km})$ with a somewhat broader height integration of $8 \mathrm{~km}$.

Both data sets are similar within the limits of the measurements and the trends agree well showing the background winds initially of $\sim 10 \mathrm{~m} / \mathrm{s}$ opposing the wave motion but later reversing and increasing to $\sim 50 \mathrm{~m} / \mathrm{s}$ during the 4 -h interval when the wave was present. The horizontal bar indicates the time of observation of this event in the $\mathrm{OH}$ emission and its mean observed phase speed of $\sim 60 \mathrm{~m} / \mathrm{s}$. Although the background wind in the direction of motion of the wave increased significantly (by $\sim 60 \mathrm{~m} / \mathrm{s}$ ) during its transition over northern Scandinavia, the observed phase speed was always higher than the background winds as measured at the $\mathrm{OH}$, $\mathrm{Na}$, and $\mathrm{O}_{2}$ heights.

Figure 8 plots the intrinsic phase speed (i.e. its speed relative to the background wind) and the intrinsic period for this wave event. During the $4 \mathrm{~h}$ of coincident observations both radar data sets indicate an intrinsic phase speed of initially $\sim 70-90 \mathrm{~m} / \mathrm{s}$ reducing to $\sim 50-60 \mathrm{~m} / \mathrm{s}$ towards the end of the wave observation. During this time the intrinsic wave period increased from $\sim 8$ to $14 \mathrm{~min}$. In comparison, a similar analysis of wave 1 event (not shown) indicated an intrinsic phase speed of $\sim 60 \mathrm{~m} / \mathrm{s}$ and a mean intrinsic period of $\sim 10 \mathrm{~min}$ (see Table 1).

\subsection{9/30 January}

The imager was operated from 16:00 UT to 05:30 UT on this night. However, the airglow measurements were again compromised by persistent auroral activity. A distinct, but relatively faint band-type event was observed for $\sim 2$-hrs interval from 21:20 to 23:30 UT. The wave pattern was extensive, and evident primarily in the $\mathrm{Na}$ emission, which was much less effected by auroral emissions. This is illustrated in Fig. 9 which shows two images of the night sky around 23:00 UT. The wave pattern is quite evident in the $\mathrm{Na}$ emission (right image) which was essentially free of auroral emissions during this period while the broadband $\mathrm{OH}$ data (left image) were dominated by extensive auroral features that often prevented meaningful measurements in the $\mathrm{OH}$, and the $\mathrm{O}_{2}$ airglow emissions. Figure 10 maps this wave event in the $\mathrm{Na}$ emission at 23:06 UT. The wave was observed to progress towards the $\sim \mathrm{SW}$ with a similar heading and horizontal wavelength ( $\sim 28 \mathrm{~km})$ as wave 1 (observed on 27/28 January), but with a significantly lower observed phase speed of $\sim 30 \mathrm{~m} / \mathrm{s}$. As this pattern was also extensive we have again compared its intrinsic parameters using both radar data sets.

Figure 11 is analogous to Fig. 7 and shows the background winds as measured by each radar in the direction of motion of this wave event. On this night the Esrange data indicated a mean value of $\sim-30$ to $-40 \mathrm{~m} / \mathrm{s}$ while the Andenes radar suggested a mean wind speed of $\sim-20 \mathrm{~m} / \mathrm{s}$. However, both data sets show that the winds were clearly directed opposite to that of the wave motion for the duration of the event (indicated by the horizontal bar). Figure 12 plots intrinsic parameters for this event. On average, both of these data sets suggest an intrinsic phase speed around $\sim 40-60 \mathrm{~m} / \mathrm{s}$ and an intrinsic wave period of $\sim 6-12 \mathrm{~min}$. Within the measurement uncertainties these intrinsic parameters are very similar to both wave events observed on 27/28 January. However, the radar data on the 29/30 January indicate a systematic difference in the 


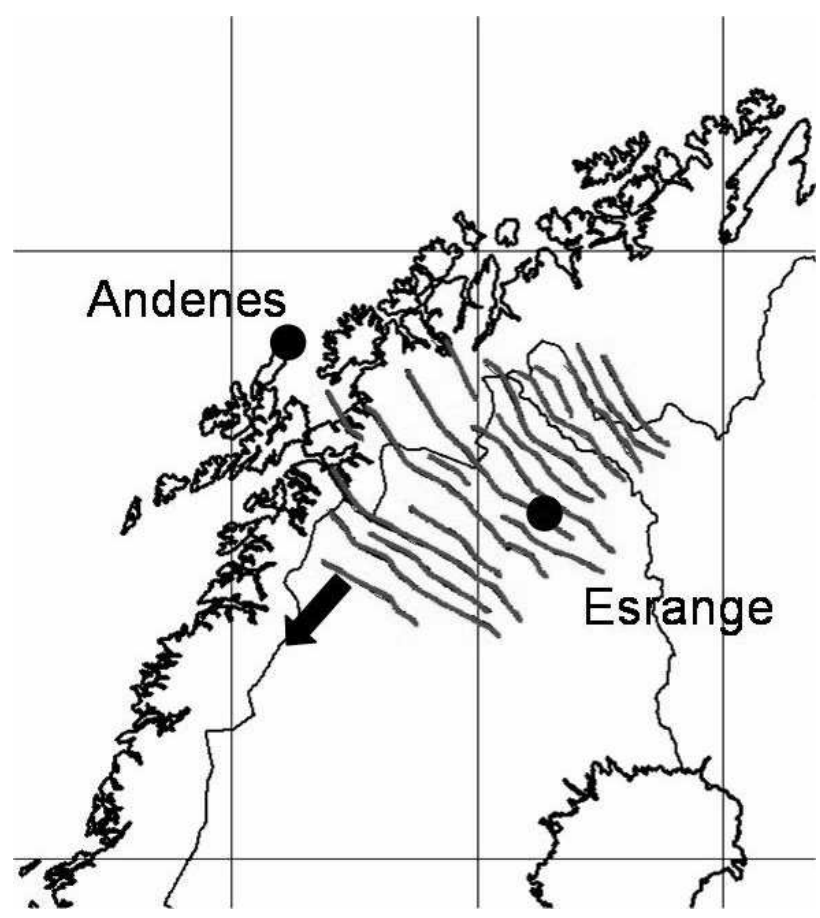

Fig. 10. This map shows the $29 / 30$ January wave event in the $\mathrm{Na}$ emission mapped onto the same geographical as Fig. 4. The wave progressed overhead at Esrange with a SW heading (indicated by the arrow).

intrinsic phase speed of $\sim 20 \mathrm{~m} / \mathrm{s}$ as determined at Andenes and Esrange suggesting a possible gradient in the wind field across the northern Scandinavian mountains which separate the two sites.

\section{$4.3 \quad 30 / 31$ January}

On this night airglow measurements were made for $\sim 5.5 \mathrm{~h}$ from $\sim$ 17:30 to 23:10 UT. Two wave events were observed during this period. The first event consisted of a limited set (3 crests) of faint bands observed at low elevations propagating towards the SE for approximately one hour with a high phase speed of $\sim 72 \mathrm{~m} / \mathrm{s}$. The second event comprised an unusually extensive set of coherent short horizontal wavelength waves $(\sim 10-14 \mathrm{~km})$ that was observed for over $\sim 90 \mathrm{~min}$ from 22:10 UT eventually progressing out of the camera field of view as the auroral activity increased.

The first wave event was observed only in the $\mathrm{OH}$ and the $\mathrm{Na}$ emissions with no apparent $\mathrm{O}_{2}$ signature. Due to the low contrast of this event spectral analysis was only possible using the broadband $\mathrm{OH}$ data. Figure 13 shows the now familiar plot of horizontal wind speed centered around the $\mathrm{OH}$ peak in the direction of the first wave event. On this occasion the background wind field as detected at both sites exhibited an almost uniform increase during the course of the night. The higher temporal resolution Esrange data show

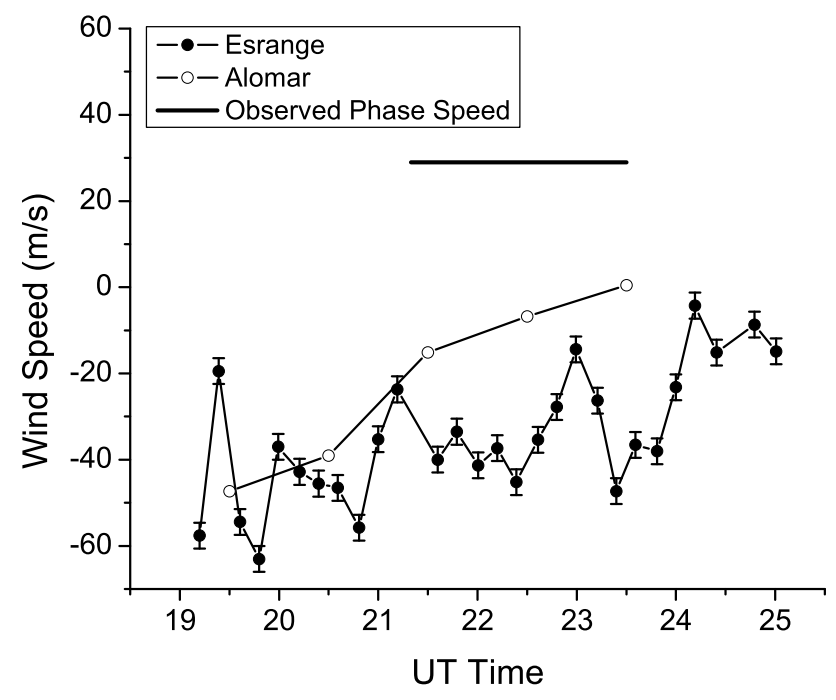

Fig. 11. Plot showing the horizontal wind field in the direction of the January 29/30 wave as a function of time. Both wind fields over Andenes and Esrange are shown. As before, the horizontal line indicates the duration of the wave and its observed phase speed.

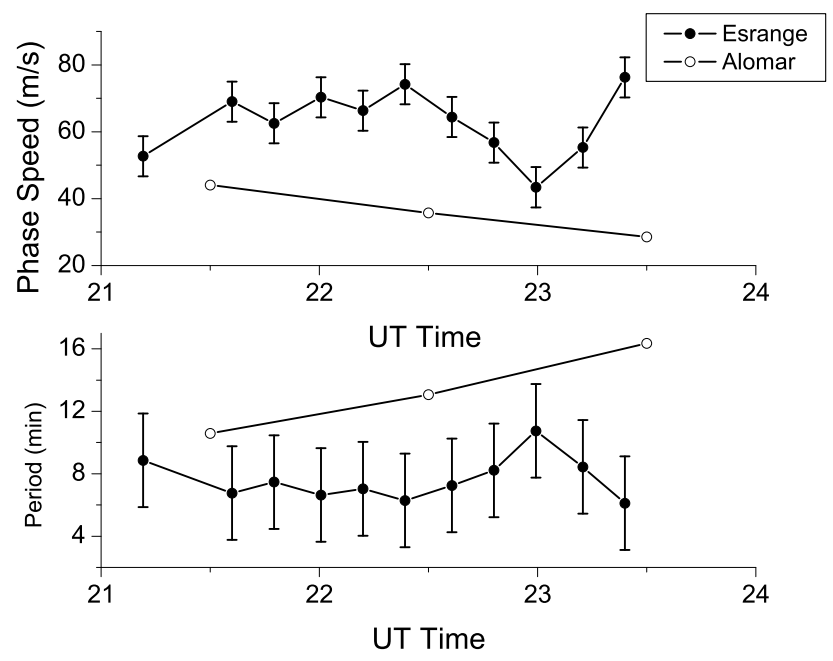

Fig. 12. Derived intrinsic parameters for the 29/30 January wave event using the Esrange and Andenes wind data sets. The top panel plots the intrinsic phase speed while the bottom panel shows the intrinsic period. The estimated uncertainties are $\pm 6 \mathrm{~m} / \mathrm{s}$ for the intrinsic phase speed and \pm 3 -min for the intrinsic period.

significant perturbations around this trend and, in particular, are characterized by a strong peak around 21:45 UT, followed by a general decrease back to the levels observed at Andenes. As before, the horizontal bar shows the duration and observed phase speed of this faint event observed from $\sim 20: 50$ to 21:40 UT. This event was detected over northern Finland mainly to the east of the Esrange radar field of view, but well outside the Andenes radar observing region. Focusing on the Esrange wind data the figure shows 


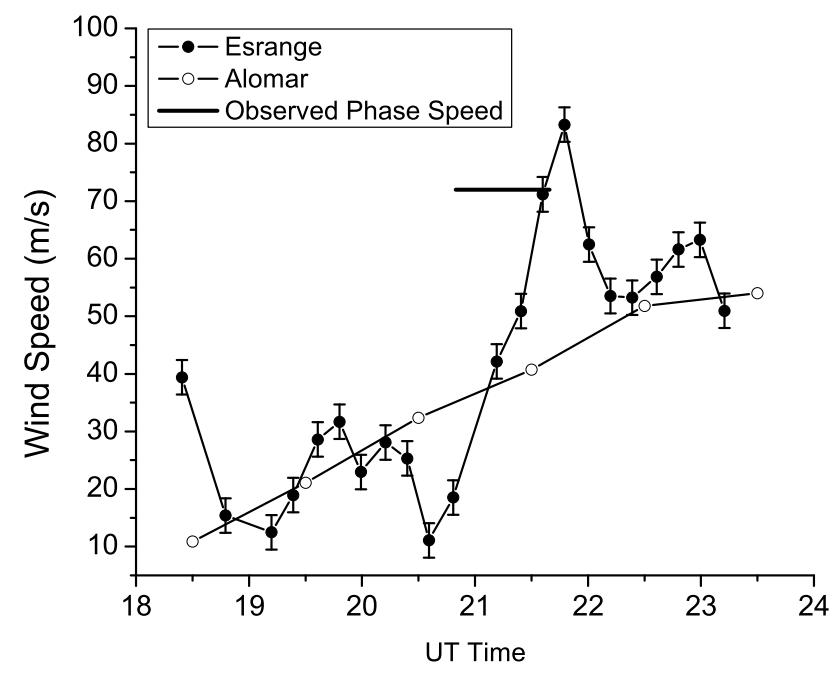

Fig. 13. Plot showing the horizontal wind in the direction of wave propagation for the band event observed on 30/31 January. As before, the horizontal line indicates the duration of the event and its observed phase speed.

the wave event was present during the period when the wind in the wave direction increased rapidly $(\sim 10$ to $85 \mathrm{~m} / \mathrm{s})$ exceeding its observed phase speed around 21:40 UT. These data strongly suggest the possibility that this event encountered a critical level around this time. Critical levels occur when the intrinsic phase speed reduces to zero. This is illustrated in Fig. 14 which shows the intrinsic phase speed of this event decreasing rapidly from $\sim 50 \mathrm{~m} / \mathrm{s}$ to zero during the $\sim 1$-h that it was observed. As a gravity wave approaches a critical level, its intrinsic frequency and vertical wavelength decreases towards zero, causing it to contribute smaller airglow perturbations and to result in instability and dissipation (Fritts and Alexander, 2003). The fact that this wave event was no longer evident after achieving a critical level condition supports this possibility. However, as the already mentioned, the wave was mainly seen at low elevations (to the $\mathrm{NE}$ ) propagating away from Esrange and it is also possible that it was later lost in the increasing auroral background.

Table 1 summarizes the average observed and intrinsic wave parameters for all these band-type data. The table also includes measurements of an extensive, but much shorter horizontal wavelength event (observed on 30/31 January) which are usually associated with short-lived ripple-type wave events (see Hecht, 2004a and references therein). Due to the unusual nature of this wave it is considered separately in the following discussion.

\section{Discussion}

These measurements, though limited in number, provide a good measure of the characteristics and type of waves present

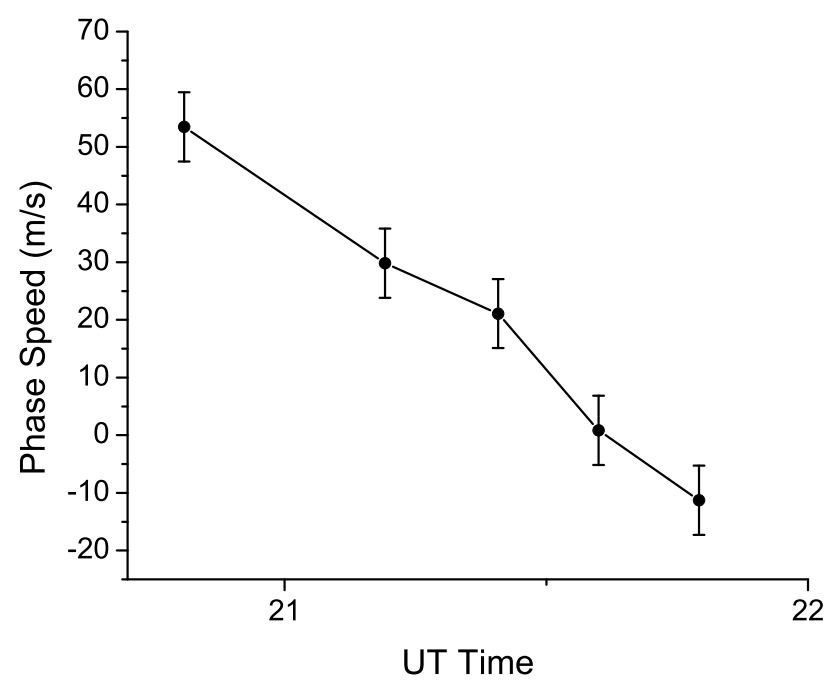

Fig. 14. Plot showing the intrinsic phase speed as a function of time for the band event observed on 30/31 January. The intrinsic values are derived using the Esrange radar data.

in the high latitude MLT region during the MaCWAVE campaign. The observed horizontal wavelengths, phase speeds, and periodicities are quite consistent with short-period measurements from mid- and low latitude (Swenson and Mende, 1994; Taylor et al., 1995b; Wu and Killeen, 1996; Taylor et al., 1997; Nakamura et al., 1999; Walterscheid et al., 1999; Smith et al., 2000; Hecht et al., 2001a,b; Ejiri et al., 2003; Medeiros et al., 2003; Nakamura et al., 2003; Pautet et al., 2005). However, the observed phase speeds are all relatively high $(\sim 40-70 \mathrm{~m} / \mathrm{s})$ and are therefore not thought to be associated with orographic wave forcing. The presence of a stratospheric warming during this period created a zero wind region which acted to block the upward propagation of any mountain waves (Blum et al., 2006). The absence of waves exhibiting low phase speeds in our data is in good agreement with this prevailing condition. However, as our data show, gravity waves having other origins and exhibiting significantly higher phase speeds were able to reach the highlatitude MLT region during this period.

Figure 15 plots observed phase speeds versus azimuth for the three nights of data. These limited data clearly show a preference for southward wave propagation over a relatively restricted azimuthal range extending from SW to SE. In each plot the contour indicates a boundary within which waves generated in the lower atmosphere would not be expected to be observed due to critical level filtering by the intervening wind field (e.g. Taylor et al., 1993; Medeiros et al., 2003; Wang et al., 2006). This analysis used available wind measurements obtained during the MaCWAVE campaign using sounding rocket falling sphere data, an example of which is shown later in Fig. 21 (more information on the falling sphere technique can be found in Schmidlin et al., 1991). Figure 15a shows the cumulative results of wind filtering up to the $\mathrm{OH}$ 
(a)

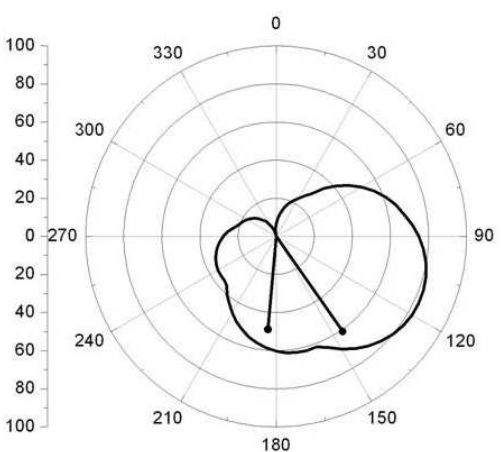

(c)

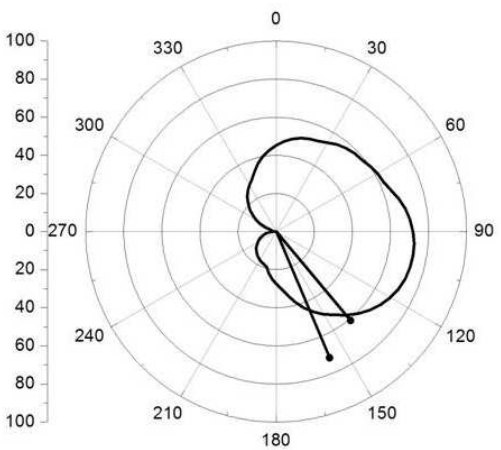

(b)

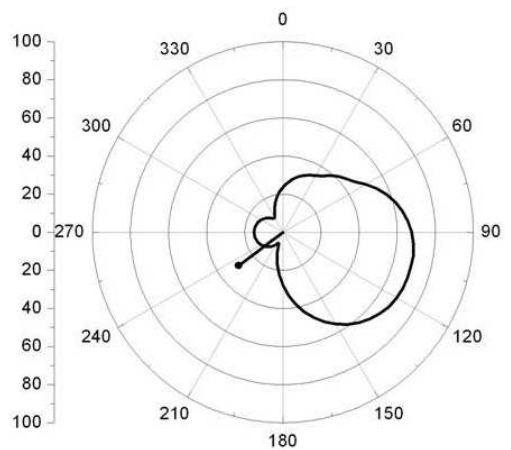

(d)

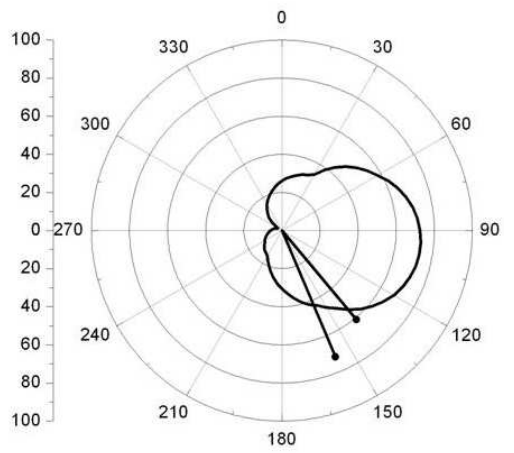

Fig. 15. Azimuthal plots showing the observed phase speeds versus the propagation direction for the three nights of observations. The contours show the wind blocking regions computed using falling sphere wind measurements. (a) shows the two events on 27/28 January while (b) shows the event on 29/30 January. (c) and (d) show the band and small-scale (ripple) events observed on 30/31 January with blocking regions calculated at 13:00 UT and 21:00 UT, respectively.

layer centered at $\sim 87 \mathrm{~km}$ for $27 / 28$ January using wind data at $\sim 15: 00$ UT $\sim 1$-h prior to the wave measurements. Both wave events appear close to the boundary expected for critical level filtering $(\sim 60 \mathrm{~m} / \mathrm{s})$. However, the uncertainty in the observed phase speeds and wind measurements leaves open the probability that they may both have easily escaped critical level absorption due to the temporally-evolving large-scale winds. Figure $15 \mathrm{~b}$ shows a similar plot for the wave observed on 29/30 January. Unfortunately, no falling sphere wind data were available around the time of this event $(\sim 21: 30 \mathrm{UT})$, and the blocking contour was calculated using wind measurements from earlier in the day (13:00 UT). Although the observed phase speed was lower $(29 \mathrm{~m} / \mathrm{s})$ the plot shows that the wave propagated in an opposite direction to the expected wind blocking area. Similar analyses using data from other nights during the campaign (e.g. Fig. 15d) show that the $\mathrm{S}-\mathrm{SW}$ direction remained essential free from blocking prior to the time of the wave observation and hence this event was almost certainly not effected by the background winds.

Figures $15 \mathrm{c}$ and $\mathrm{d}$ show the wind filtering analysis at two different times ( $\sim$ 13:00 UT and $\sim 21: 00 \mathrm{UT}$, respectively) for the waves observed on 30/31 January (including the smallscale event). In both instances the waves were observed to be outside the expected exclusion region. Thus, each of
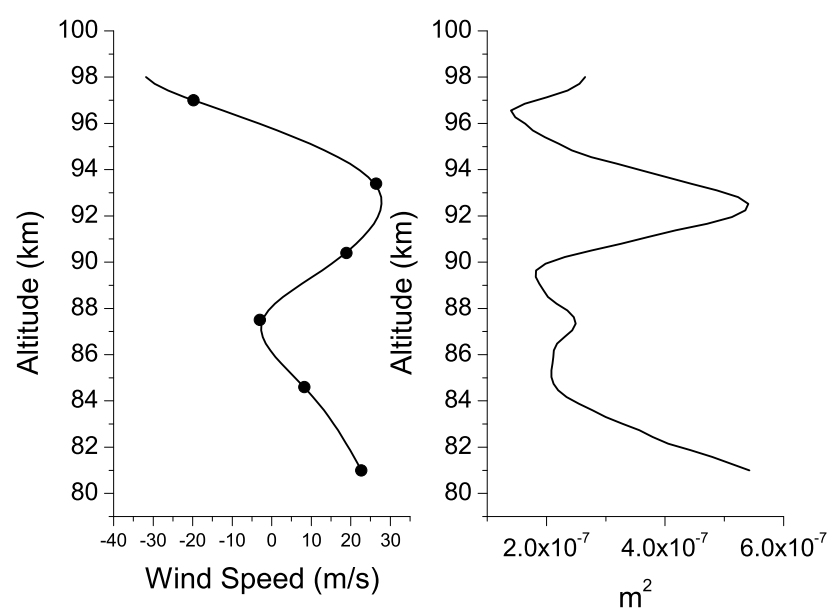

Fig. 16. Left plot shows the vertical wind profile (Esrange radar data) in the direction of wave 1 observed on 27/28 January at 16:00 UT. The sign indicates the direction of the wind relative to the wave motion (positive in same direction). Right plot shows the squared value of the vertical wavenumber as a function of height. The positive value for $m^{2}$ throughout the emission layer heights is indicative of a freely propagating wave. 

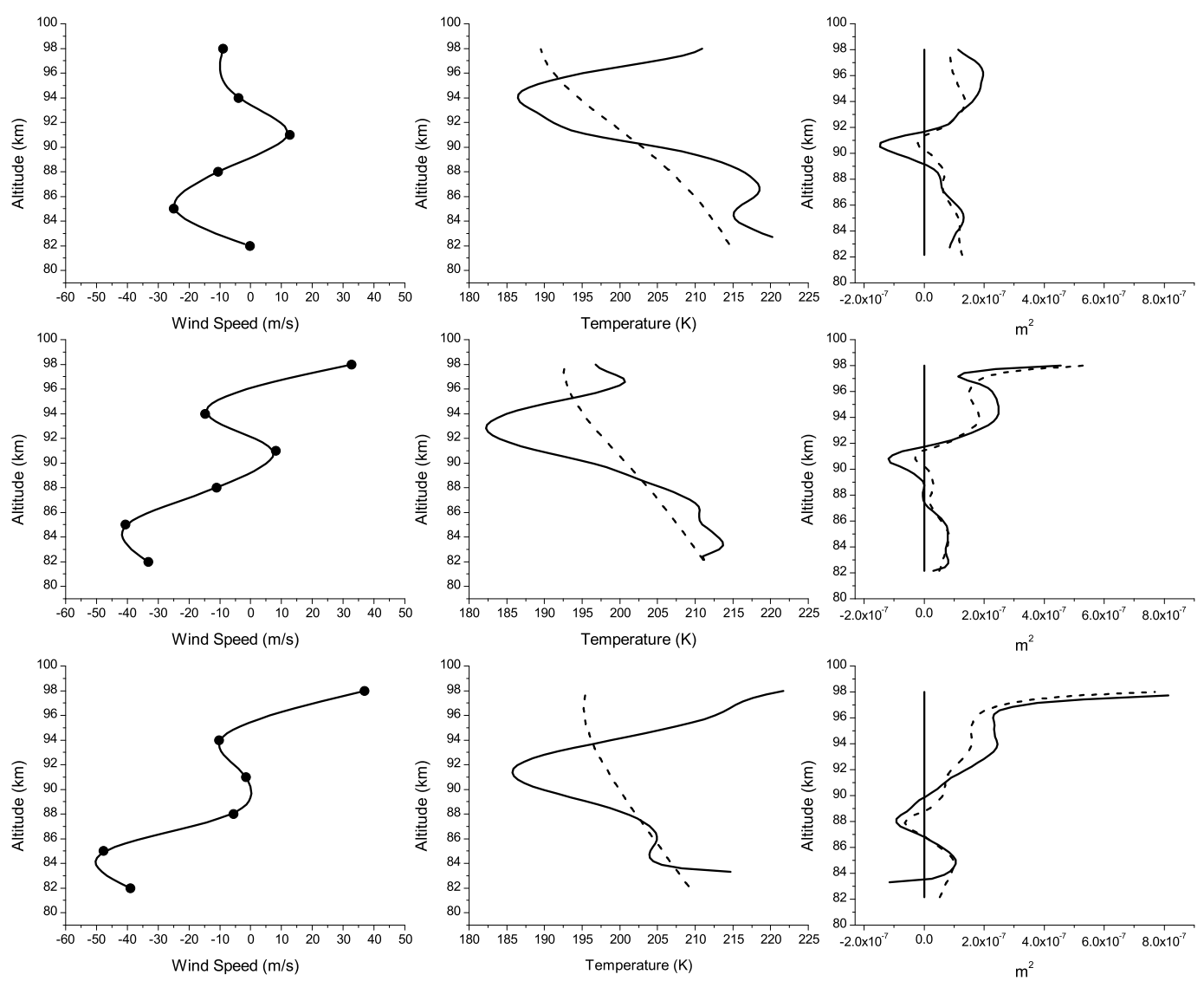

Fig. 17. Plots showing the evolution of the wind,temperature, and $m^{2}$ fields over a 3-h period (17:00, 18:00, 19:00 UT) for wave 2 observed on 27/28 January using radar and lidar data from Andenes/ALOMAR. The left column plots the radar projected wind field, the center column shows the lidar temperature field (solid line) and MSIS temperature (dashed line). The right column shows the calculated $m^{2}$ profile using lidar temperature (solid) and MSIS model data (dashed)

these mesospheric wave events observed during this campaign have the potential to be freely propagating waves generated in the lower atmosphere.

Though not discussed further here, our data suggest a main source region for these waves to the north of Esrange, most probably at a range of a few hundreds of kilometers (assuming freely propagating waves of tropospheric origin - Taylor and Henriksen, 1989). However, the possibility also exists for horizontal wave propagation over much longer distances if the waves were ducted in nature (Walterscheid et al., 1999; Hecht et al., 2004b; Pautet et al., 2005). Waves can be ducted at maxima in the wind field in the plane of wave propagation, termed Doppler ducting (Chimonas and Hines, 1986; Wang and Tuan, 1988; Isler et al., 1997), by thermal ducts at sharp temperature inversions (Walterscheid et al., 1999), or by a combination of these processes (Fritts and Yuan, 1989b). Due to their relatively small scale sizes, short period gravity waves are considered prone to both forms of ducting and convincing evidence of ducted wave motions at MLT heights has been reported at mid- and low latitudes (Isler et al., 1997;
Walterscheid et al., 1999; Hecht et al., 2001a, 2004b; Pautet et al., 2005).

We can use the available MLT meteor wind radar and lidar data to investigate the possibility of Doppler ducting of the observed wave motions during the MaCWAVE campaign. The theory of Doppler ducting for linear gravity waves is well-developed (e.g. Chimonas and Hines, 1986; Fritts and Yuan, 1989b). For wind and temperature profiles that vary slowly with respect to altitude, and for waves with phase speeds much less than sound speed, the WKB solution to the Taylor-Goldstein equation is (Nappo, 2002).

$$
m^{2}=\frac{N^{2}}{\left(c-u_{0}\right)^{2}}+\frac{u_{0}^{\prime \prime}}{\left(c-u_{0}\right)}-\frac{1}{H_{s}} \frac{u_{0}^{\prime}}{\left(c-u_{0}\right)}-\frac{1}{4 H_{s}^{2}}-k^{2}
$$

where $N$ is the Brunt-Väisälä frequency, $c$ is the observed phase speed, $u_{0}$ is the background wind in the wave direction, $H_{s}$ is the scale height, and $k$ is the horizontal wave number. For the wave events described herein the two first terms (the buoyancy and curvature term, respectively) are typically of the order of $10^{-7} \mathrm{~m}^{-2}$, while the other terms are of the order 
of $10^{-8} \mathrm{~m}^{-2}$, though $k^{2}$ can play a major role when $N^{2}$ is small or $c-u_{0}$ is large. Hence, the first two terms and the last term are typically dominant. In the above equation, the Brunt-Väisälä frequency was calculated using:

$N^{2}=\frac{g}{T}\left(\frac{d T}{d z}-\Gamma\right)$

where $\frac{d T}{d z}$ is the local temperature gradient, $g=9.54 \mathrm{~m} / \mathrm{s}^{2}$ and the adiabatic lapse rate, $\Gamma=9.5 \mathrm{~K} / \mathrm{km}$. The scale height was calculated using:

$H_{s}=\frac{R T}{g}$

where $R=287 \mathrm{~J} /(\mathrm{kg} \cdot \mathrm{K})$ is the universal gas constant.

For 27/28 January lidar temperature measurements were available from ALOMAR and have been used to calculate $N$ and $H_{s}$. For the other two nights MSIS temperature model data were used to estimate these parameters.

As discussed by Isler et al. (1997), if $m^{2}>0$ throughout the MLT region the wave is freely propagating. If $m^{2}<0$ throughout this region the wave is evanescent in nature and cannot freely propagate and its amplitude will decay exponentially with altitude. If the variation in the wind field or $N^{2}$ is such as to create a region of $m^{2}>0$ bounded by regions of $m^{2}<0$ then the wave can be trapped or ducted.

Figure 16 (left) shows the height profile of the Esrange meteor winds for wave 1 observed on 27/28 January at 16:00 UT (when the wave was detected in all four nightglow emissions). The profile shows the background winds in the observed direction of wave motion $\left(185^{\circ}\right)$ derived from the sixgate data (81.1-96.8 km, see Sect. 3) and plotted using a smoothed spline interpolation. The profile exhibits a distinct minimum around $87 \mathrm{~km}$ followed by a maximum around $93 \mathrm{~km}$. Figure 16 (right) shows the corresponding $\mathrm{m}^{2}$ profile over this altitude range. As $m^{2}$ was clearly positive throughout this altitude range this indicates the wave was freely propagating at this time. Although the wind field increased somewhat during the 90 minute interval that the wave was observed (see Fig. 7), similar $m^{2}$ results (not shown) were obtained indicating that the wave remained freely propagating.

Figure 17 show the results of a similar analysis performed on the second wave event observed on this night that was also evident in all four emissions. This wave was observed for over 3-hrs initially overhead at Andenes and later Esrange. To illustrate the varying wind conditions encountered by the wave during this time $\mathrm{m}^{2}$ profiles were calculated at hourly intervals (17:00, 18:00, and 19:00 UT). Furthermore, to investigate the effects of temperature variability we have used available lidar data for this night and compared these results with MSIS model data (dotted lines). A maximum in the projected wind field in the direction of wave motion was again found (this time around $90 \mathrm{~km}$ ). This coincided with a strong negative gradient in the temperature field, which created the potential for a narrow evanescent region around $90 \mathrm{~km}$. This
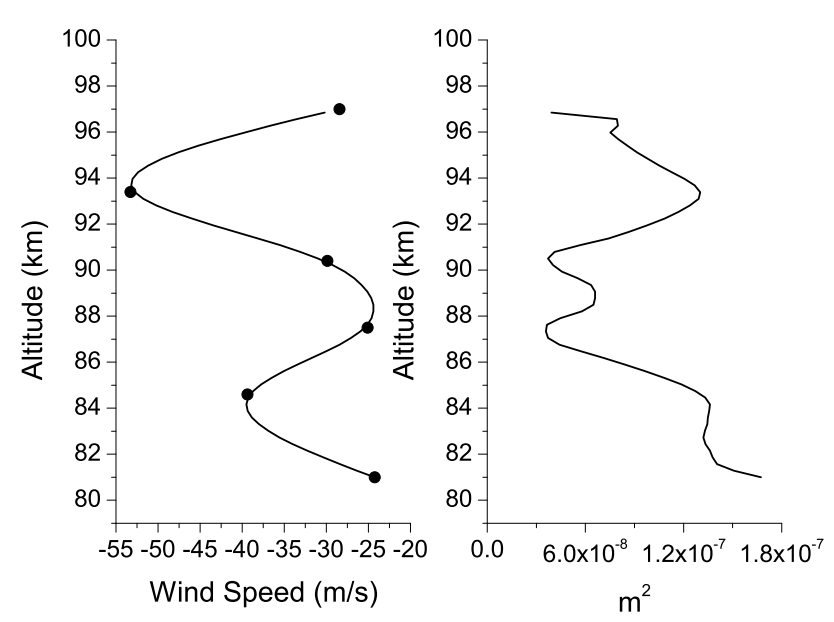

Fig. 18. Projected Esrange winds (left) and calculated $m^{2}$ (right) profiles for the 29/30 January event at 23:00 UT. The $\mathrm{m}^{2}$ values are positive over the entire altitude range indicating a freely propagating wave.

is evident in all three of the $m^{2}$ plots which show a narrow $(\sim 2 \mathrm{~km})$ evanescent region $\left(m^{2}<0\right)$ located near $90 \mathrm{~km}$. However, as $\mathrm{m}^{2}$ was pre-dominantly positive throughout the MLT region and the wave's mean vertical wavelength $\lambda_{z}$ was $\sim 20 \mathrm{~km}$, this suggests that it would most likely penetrate this evanescent layer and was essentially freely propagating within the $80-100 \mathrm{~km}$ region. (Note, a repeat analysis using MSIS temperature data yielded very similar $m^{2}$ results (dotted lines) suggesting that the MSIS data were quite applicable for this investigation.)

Figure 18 shows an $\mathrm{m}^{2}$ analysis of the wave event observed on 29/30 January at 23:00 UT. Throughout the $\sim 2$-h duration of this event the wave was also determined to be freely propagating. This event was observed primarily in the $\mathrm{Na}$ emission and appeared to be somewhat fainter than the two waves observed on 27/28 January. The band event observed on 30/31 January was unfortunately not suitable for this type of analysis as the higher altitude wind data were incomplete, which restricted a reasonable estimate of the wind profile as a function of altitude.

We now turn our attention to the small-scale wave event observed on 30/31 January. Figure 19 shows two maps of this unusual wave event as observed in the $\mathrm{OH}$ and $\mathrm{Na}$ emissions nearly simultaneously $\sim 23: 20 \mathrm{UT}$. In the $\mathrm{OH}$ emission over 10 coherent wave crests were detected, oriented NE-SW and exhibiting a horizontal wavelength of $14 \pm 0.5 \mathrm{~km}$. This event was observed for $90 \mathrm{~min}$ as it progressed overhead towards the SE $\left(\sim 140^{\circ}\right)$. In comparison, the Na data shows a similarly oriented coherent wave pattern traveling on the same heading but exhibiting a significantly shorter horizontal wavelength of $10 \pm 0.5 \mathrm{~km}$. (Note, the $\mathrm{OH}$ pattern also exhibited some rotation of the leading part of the wave field by $\sim 20^{\circ}$ as indicated by the arrows in the figure.) 

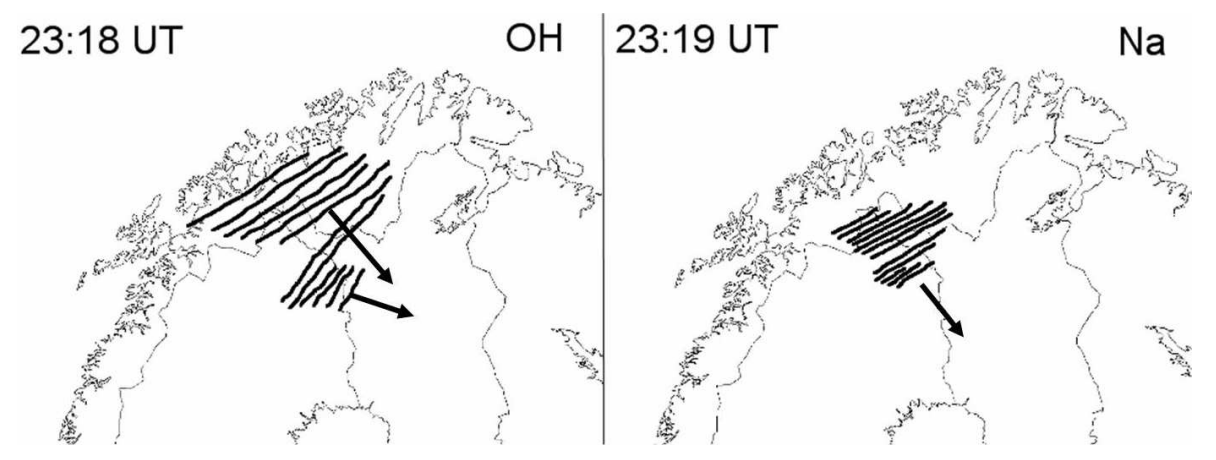

Fig. 19. Map of small-scale (ripple) event observed on 30/31 Janaury for the $\mathrm{OH}$ (left) and $\mathrm{Na}$ (right) emissions. The $\mathrm{OH}$ pattern exhibited a larger horizontal wavelength $(14 \mathrm{~km})$ as compared to the $\mathrm{Na}$ data $(10 \mathrm{~km})$ and was more extensive.

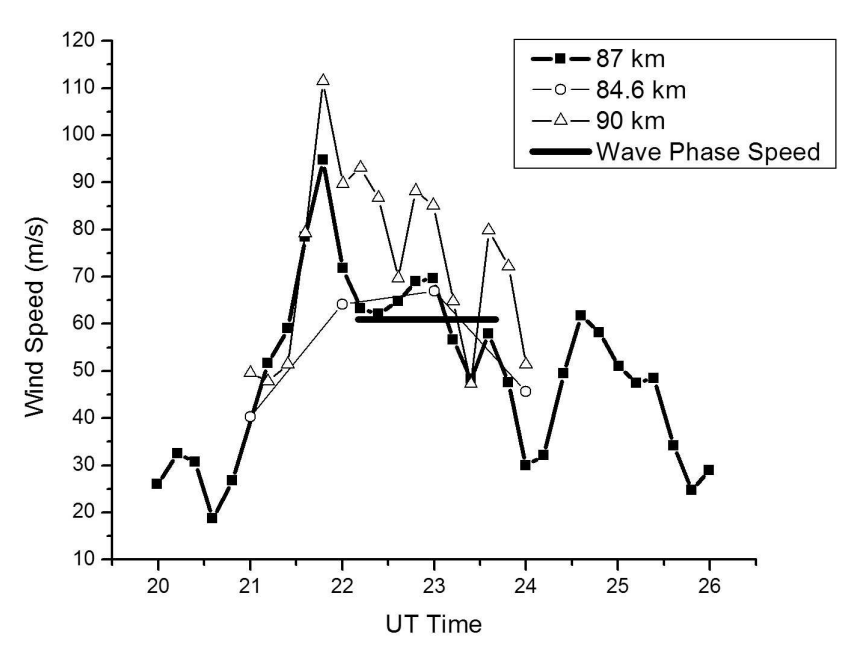

Fig. 20. Plot showing the background wind projected in the direction of the motion of the small-scale wave event observed on 30/31 January. The horizontal line indicates the observed phase speed and duration of the $\mathrm{OH}$ data. The solid line (squares) shows the wind field at the nominal $\mathrm{OH}$ altitude $(\sim 87 \mathrm{~km})$ while the thin lines (circles and triangles) plots the winds at two close altitudes $(84.6$ and $90 \mathrm{~km})$ to show variations in the wind field.

Short-period freely propagating gravity waves (as described earlier herein) typically exhibit horizontal wavelengths in the $\sim 20-40 \mathrm{~km}$ range and lifetimes of up to several hours. Another type of airglow wave pattern termed "ripples" has been reported on numerous prior occasions (e.g. Peterson, 1979; Taylor and Hapgood, 1990). These are short wavelength (typically $5-15 \mathrm{~km}$ ) spatially isolated, transient events (lifetimes $\sim$ few tens of minutes) that have been associated with in-situ wave generation (e.g. Hecht, 2004a and references therein). However, observations of long-lived spatial extensive ripple-type events (as shown in Fig. 19) are rare (Taylor et al., 1997; Medeiros et al., 2003). The phase speed of this event, as measured in the $\mathrm{OH}$ emission, was $\sim 60 \mathrm{~m} / \mathrm{s}$ yielding an observed period of $4 \pm 1 \mathrm{~min}$ (see

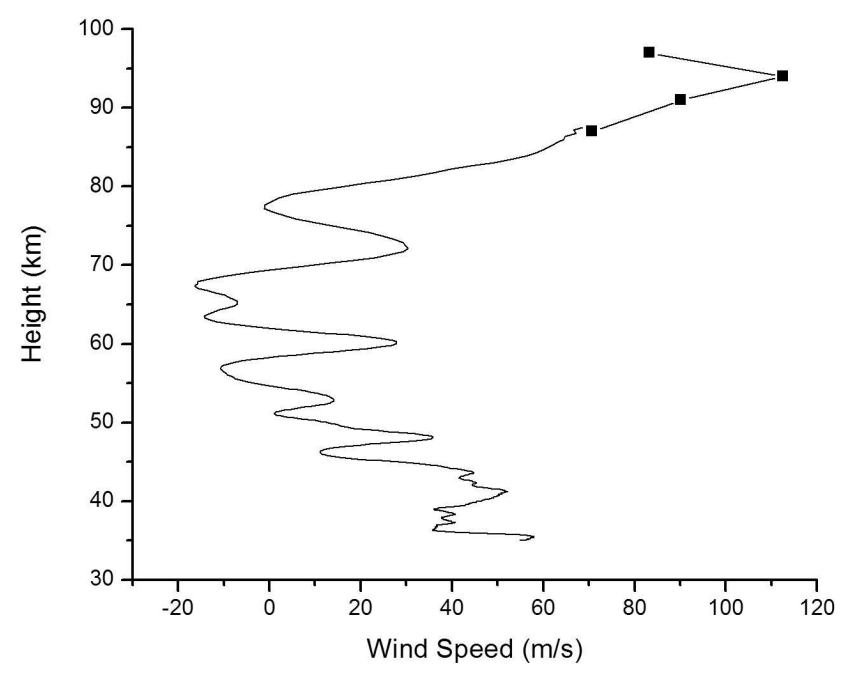

Fig. 21. Plot showing combination of falling sphere and Esrange meteor wind data projected onto the apparent propagation direction of the small-scale (ripple) wave event observed on 30/31 January. The two data sets agrees well near the overlap point and together show a strong wind shear $(\sim 110 \mathrm{~m} / \mathrm{s}$ over $10 \mathrm{~km})$ spanning the $\mathrm{OH}$ and $\mathrm{Na}$ airglow layers.

Table 1). Of particular interest here is the investigation of the background wind field in which this event existed. This is shown in Fig. 20 which plots the horizontal wind at the nominal $\mathrm{OH}$ emission height $(87 \mathrm{~km})$ in the direction of wave motion $\left(\sim 140^{\circ}\right)$ during the course of the night. As in previous figures the horizontal bar represents the observed phase speed and the event duration ( $\sim 90$-min). It is immediately evident that the "OH winds" and the "OH waves" exhibited very similar values indicating that the wave was embedded in the background flow suggesting in-situ wave generation possibly by instability processes (e.g. Fritts et al., 1993).

Fortunately, on this occasion, falling sphere rocket data (ES03SL48) are also available around the time of the wave measurements. Figure 21 shows a composite plot of the projected background winds obtained by the falling sphere 
measurement and the Esrange meteor radar measurement around 22:00 UT. Together these data show a strong wind shear of about $110 \mathrm{~m} / \mathrm{s}$ over the altitude range of $80-95 \mathrm{~km}$. This large-scale wind shear along the direction of apparent wave motion spans both the $\mathrm{OH}$ and $\mathrm{Na}$ emission altitudes and the observed speeds of the small-scale waves. Thus, this shear immediately precludes both propagating and ducted wave motions. Instead, the shear is most suggestive of a Kelvin-Helmholtz (KH) shear instability, likely having a separate response (including detailed structure, wavelength, and apparent direction of motion) at the two observation altitudes. This is supported by the different wavelengths and orientations of the wave patterns in the two airglow layers. $\mathrm{KH}$ instabilities often arise as a response to a low-frequency wave perturbation of a large-scale shear that is itself propagating in an orthogonal direction and thus does not encounter its own critical level. Indeed, the $\mathrm{OH}$ wave structures shown in Fig. 19 are suggestive of a somewhat different orientation and wavelength in different spatial regions at the same altitude. Both the mean wavelengths of the $\mathrm{OH}(14 \mathrm{~km})$ and $\mathrm{Na}(10 \mathrm{~km})$ patterns and their temporal extent ( $\sim 90-\mathrm{min})$ are on the large side for what is expected for $\mathrm{KH}$ instabilities. However, these values can be accommodated if the initial Richardson number of the flow was close to the unstable value of 0.25 , resulting in an instability that evolved slowly with time and achieved a much shallower aspect ratio than more transient instabilities resulting from significantly lower Richardson numbers.

\section{Summary}

All-sky monochromatic image measurements of the highlatitude $\mathrm{OH}, \mathrm{Na}$, and $\mathrm{O}_{2}$ nightglow emissions have been used to investigate the characteristics and propagation of shortperiod gravity wave events observed during the MaCWAVE winter campaign. Despite the frequent presence of aurora, several distinct wave events were measured and their horizontal characteristics were found to be similar to mesospheric waves observed at other latitudes. In particular, the observed phase speeds ranged from $\sim 30$ to $70 \mathrm{~m} / \mathrm{s}$ and were predominantly southward consistent with wave generation mainly to the north of Scandinavia rather than by strong orographic forcing over the Scandinavian mountains separating the two observing sites at Andenes and Esrange.

Coincident meteor wind data and lidar temperatures have been used to perform a novel two-station investigation of the intrinsic properties of these waves as a function of time and to study their propagation. This analysis indicates that all of the band-type patterns were freely propagating throughout the MLT region. Although our measurements were limited to a short $\sim 5$ day period, they suggest the frequent presence of upward propagating gravity waves at high wintertime latitudes. Unusual extensive smaller-scale structures were also observed. These were found to be located in a region of strong wind shear and were judged to be due to a large-scale $\mathrm{KH}$ instability rather than propagating or ducted gravity waves. Further coordinated wind, temperature, and wave measurements are needed to investigate in detail the nature of the dominant short-period wave motions. If freely propagating wave motions are found to prevail then these results could have significant implications on the vertical transport of horizontal momentum by short-period gravity waves at high northern latitudes.

Acknowledgements. We are most grateful to the Esrange facility and staff for their considerable support during the MaCWAVE measurements program. In particular, we wish to thank Ola Widell for his great help in organizing our use of the Esrange optical facilities. The analysis of the USU optical data was supported (in part) by NSF grants OPP-9816465, ANT-0338364, and ATM-0437440. The meteor radar operations at Andenes were supported, in part by a European Union grant HPRI-CT-1999-00002. D. C. Fritts was supported by AF0SR contract F49620-03-C-0045 and NSF grant ATM-0137354. The lidar operations at ALOMAR were supported by NSF grant ATM-0436703.

Topical Editor U.-P. Hoppe thanks two referees for their help in evaluating this paper.

\section{References}

Bacmeister, J. T., Newman, P. A., Gary, B. L., and Chan, K. R.: An algorithm for forecasting mountain wave-related turbulence in the stratosphere, Weath. Forecst., 9, 241-253, 1994.

Blum, U. G., Baumgarten, A., Schöch, A., Kirkwood, S., Naujokat, B., and Fricke, K. H.: The atmospheric background situation in northern Scandinavia during January/February 2003 in the context of the MaCWAVE campaign, Ann. Geophys., this issue, 2006.

Brown, L. B, Gerrard, A. J., Meriwether, J. W., and Makela, J. J.: All-sky imaging observations of mesospheric fronts in OI $557.7 \mathrm{~nm}$ and broadband $\mathrm{OH}$ airglow emissions: Analysis of frontal structure, atmospheric background conditions, and potential sourcing mechanism, J. Geophys. Res., 109, D19104, doi:10.1029/2003JD004223, 2004.

Chimonas, G. and Hines, C. O.: Doppler ducting of atmospheric gravity waves, J. Geophys, Res., 91, 1219-1230, 1986.

Clairemidi, J., Hersé, M., and Moreels, G.: Bi-dimensional observations of waves near the mesopause at auroral latitudes, Planet. Space. Sci., 33, 1013-1022, 1985.

Coble, M. R., Papen, C, and Gardner, C. S.: Computing twodimensional unambiguous horizontal wavenumber spectra from $\mathrm{OH}$ airglow images, IEEE Trans. on geoscience and remote sensing, 36, 368-382, 1998.

Dunkerton, T. J.: Stochastic parameterization of gravity wave stress, J. Atmos. Sci., 39, 1711-1725, 1982.

Ejiri, M. K., Shiokawa, K., Ogawa, T., Igarashi, K., Nakamura, T., and Tsuda, T.: Statistical study of short-period gravity waves in $\mathrm{OH}$ and OI nightglow images at two separated sites, J. Geophys. Res., 108, doi:10.1029/2002JD002795, 2003.

Fritts, D. C. and Vincent, R. A.: Mesospheric momentum flux studies at Adelaide, Australia: Observations and a gravity wave/tidal interaction model, J. Atmos. Sci., 44, 605-619, 1987. 
Fritts, D. C. and Yuan, L.: Measurement of momentum fluxes near the summer mesopause at Poker Flat, Alaska, J. Atmos. Sci., 46, 2569-2579, 1989.

Fritts, D. C. and Yuan, L.: An analysis of gravity wave ducting in the atmosphere: Eckarts resonances in thermal and Doppler ducts, J. Geophys. Res., 94, 18 445-18 466, 1989.

Fritts, D. C., Isler, J. R., Thomas, G., and Andreassen, Ø.: Wave breaking signatures in noctilucent clouds, Geophys. Res. Lett., 20, 2039-2042, 1993.

Fritts, D. C., Palmer, T. L., Andreassen, Ø., and Lie, I.: Evolution and breakdown of Kelvin-Helmholtz billows in stratified compressible flows, part I, Comparison of two- and threedimensional flows, J. Atmos. Sci., 53, 3173-3191, 1996.

Fritts, D. C. and Alexander, M. J.: Gravity wave dynamics and effects in the middle atmosphere, Rev. Geophys. Lett., 41, doi:10.1029/2001RG000106, 2003.

Gardner, C. S., Coble, M., Papen, G. C., and Swenson, G. R.: Observations of the unambiguous 2-dimensional horizontal wave number spectrum of $\mathrm{OH}$ intensity perturbations, Geophys. Res. Lett., 23, 3739-3742, 1996.

Garcia, F. J., Taylor, M. J., and Kelley, M. C.: Two-dimensional spectral analysis of mesospheric airglow image data, Appl. Opt., 36, 7374-7385, 1997.

Garcia, R. R. and Solomon, S.: The effect of breaking gravity waves on the dynamical and chemical composition of the mesosphere and lower thermosphere, J. Geophys. Res., 90, 3850-3868, 1985.

Garcia, R. R.: Dynamics, radiation, and photochemistry in the mesosphere: Implications for the formation of noctilucent clouds, J. Geophys. Res., 94, 14 605-14 615, 1989.

Goldberg, R. A., Fritts, D. C., Williams, B. P., Lübken, F. -L., Rapp, M., Singer, W., Latteck, R., Müllemann, A., Baumgarten, G., Schmidlin, F. J., She, C.-Y., and Krueger, D. A.: The MaCWAVE/MIDAS rocket and ground-based measurements of polar summer dynamics: Overview and mean state structure, Gephys. Res. Lett., 31, L24S02, doi:10.1029/2004GL019411, 2004.

Goldberg, R. A., Fritts, D. C., Schmidlin, F. J., Williams, B. P., Croskey, C. L., Mitchell, J. D., Friedrich, M., Russel III, J. M., and Blum, U.: The MaCWAVE program to study gravity wave influences on the polar mesosphere, Ann. Geophys, this issue, 2006.

Hecht, J. H., Walterscheid, R. L., Hickey, M., and Franke, S.: Climatology and modeling of quasi-monochromatic atmospheric gravity waves observed over Urbana Illinois, J. Geophys. Res., 106(D6), 5181-5196, 2001a.

Hecht, J. H., Walterscheid, R. L., and Vincent, R. A.: Airglow observations of dynamical (wind shear-induced) instabilities over Adelaide, Australia, associated with atmospheric gravity waves, J. Geophys. Res., 106, 28,189, 2001 b.

Hecht, J. H.: Instability layers and airglow imaging, Rev. Geophys., 42, RG1001, doi:10.1029/2003RG000131, 2004a.

Hecht, J. H., Kovalam, S., May, P. T., Mills, G., Vincent, R. A., Walterscheid, R. L., and Woithe, J.: Airglow imager observations of atmospheric gravity waves at Alice Springs and Adelaide, Australia during the Darwin Area Wave Experiment (DAWEX), J. Geophys. Res., 109, D20S05, doi:10.1029/2004JD004697, 2004b.

Hedin, A. E., Fleming, E. L., Manson, A. H., Schmidlin, F. J., Avery, S. K., Clark, R. R., Franke, S. J., Fraser, G. J., Tsuda, T.,
Vial, F., and Vincent, R. A.: Empirical wind model for the upper, middle and lower atmosphere, J. Atmos. Terr. Phys., 58, 14211447, 1996.

Hocking, W. K., Fuller, B., and Vandepeer, B.: Real-time determination of meteor-related parameters utilizing modern digital technology, J. Atmos. Sol-Terr. Phys., 63, 155-169, 2001.

Holton, J. R.: The role of gravity wave-induced drag and diffusion in the momentum budget of the mesosphere, J. Atmos. Sci., 39, 791-799, 1982.

Isler, J. R, Taylor, M. J., and Fritts, D. C.: Observational evidence of wave ducting and evanescence in the mesosphere, J. Geophys. Res., 102, 26301-26313, 1997.

Larsen, M.: Winds and shears in the mesosphere and lower thermosphere: Results from dour decades of chemical release wind measurements, J. Geophys. Res., 107(A8), 1216, doi:10.1029/2001JA000218, 2002.

Medeiros, A. F., Taylor, M. J., Takahashi, H., Batista, P. P., and Gobbi, D.: An investigation of gravity wave activity in the lowerlatitude upper mesopause: Propagation direction and wind filetering, J. Geophys. Res., 108, doi:10.1029/2002JD002593, 2003.

Mitchell, N. J., Pancheva, D., Middleton, H. R., and Hagan, M. E.: Mean winds and tides in the arctic mesosphere and lower thermosphere, J. Geophys. Res., 107, doi:10.1029/2001JA900127, 2002.

Nakamura, T., Higashikawa, A., Tsuda, T., and Matsushita, Y.: Seasonal variations of gravity wave structures in $\mathrm{OH}$ airglow with a CCD imager at Shigaraki, Earth Planets Space, 51, 897-906, 1999.

Nakamura, T., Aono, T., Tsuda, T., Admiranto, A. G., Achmad, E., and Suranto: Mesospheric gravity waves over a tropical convective region observed by $\mathrm{OH}$ airglow imaging in Indonesia, Geophys. Res. Lett., 30, doi:10.1029/2003GL017619, 2003.

Nappo, C. J.: Atmospheric gravity waves, International Geophysics Series, Vol. 85, Academic Press, 2002.

Nastrom, G. D., Balsley, B. B., and Carter, D. A.: Mean meridional winds in the mid- and high-latitude summer mesospher, Geophys. Res. Lett., 9, 139-142, 1982.

Pautet, P. -D., Taylor, M. J., Liu, A. Z., and Swenson, G. R.: Climatology of shot-period gravity waves observed over northern Australia during the Darwin Area Wave Experiment (DAWEX) and their dominant source regions, J. Geophys. Res., 110, D03S90, doi:10.1029/2004JD004954, 2005.

Peterson, A. W.: Airglow events visible to the naked eye, Appl. Opt., 18, 3390-3393, 1979.

Schmidlin, F. J., Lee, H. S., and Michel, W.: The inflatable sphere: A technique for the accurate measurement of middle atmosphere temperatures, J. Geophys. Res., 96, 22 673-22 682, 1991.

She, C. Y., Vance, J. D., Williams, B. P., Krueger, D. A., Moosmüller, H., Gibson-Wilde, D., and Fritts, D. C.: Lidar studies of atmospheric dynamics near polar mesopause, EOS, 83, 289-293, 2002.

Singer, W., von Zahn, U., and Weiß, J.: Diurnal and annual variations of meteor rates at the arctic circle, Atmos. Chem. Phys., 4, 1355-1363, 2004.

Smith, S. M., Mendillo, M., Baumgardner, J., and Clark, R. R.: Mesospheric gravity wave imaging at a subauroral site: First results from Millstone Hill, J. Geophys. Res., 105, 27 119-27 130, 2000.

Swenson, G. R. and Mende, S. B.: OH emissions and gravity waves 
(including a breaking wave) in all-sky imagery from Bear Lake, Utah, Geophys. Res. Lett., 21, 2239-2242, 1994.

Taylor, M. J. and Henriksen, K.: Electromagnetic coupling in the Polar clefts and caps, edited by: Sandholt, P. E. and Egeland, A., Springer, New York, 1989.

Taylor, M. J. and Hapgood, M. A.: On the origin of ripple-type wave structure in the $\mathrm{OH}$ nightglow emission, Planet. Space. Sci., 38, 1421-1430, 1990.

Taylor, M. J., Ryan, E. H., Tuan, T. F., and Edwards, R.: Evidence of preferential directions for gravity wave propagation due to wind filtering in the middle atmosphere, J. Geophys. Res, 98, 60476057, 1993.

Taylor, M. J. and Garcia, F. J.: A two-dimensional spectral analysis of short period gravity waves imaged in the OI $(557.7 \mathrm{~nm})$ and near-infrared $\mathrm{OH}$ nightglow emissions over Arecibo, Puerto Rico, Geophys. Res. Lett., 22, 2473-2476, 1995a.

Taylor, M. J., Bishop, M. B., and Taylor, V.: All-sky measurements of short period waves imaged in the $\mathrm{OI}(557.7 \mathrm{~nm}), \mathrm{Na}(589.2 \mathrm{~nm})$ and near infrared $\mathrm{OH}$ and $\mathrm{O}_{2}(0,1)$ nightglow emissions during the ALOHA-93 campaign, Geophys. Res. Lett., 22, 2833-2386, 1995b.

Taylor, M. J., Gu, Y. Y., Tao, X., Gardner, C. S., and Bishop, M. B.: An investigation of intrinsic gravity wave signatures using coordinated lidar and nightglow image measurements, Gephys. Res. Lett., 22, 2853-2856, 1995c.
Taylor, M. J., Pendleton Jr., W. R., Clark, S., Takahashi, H., Gobbi, D., and Goldberg, R. A.: Image measurements of short-period gravity waves at equatorial latitudes, J. Geophys. Res., 102, 26283-26 229, 1997.

Walterscheid, R. L., Hecht, J. H., Vincent, R. A., Reid, I. M., Woithe, J., and Hickey, M. P.: Analysis and interpretation of airglow and radar observations of quasi-monochromatic gravity waves in the upper mesosphere and lower thermosphere over Adelaide, Australia ( $35^{\circ} \mathrm{S}, 138^{\circ}$ E), J. Atmos. Sol. Terr. Phys., 61, 461-478, 1999.

Wang, D. Y. and Tuan, T. F.: Brunt-Doppler ducting of small-period gravity waves, J. Geophys. Res, 93, 9916-9926, 1988.

Wang, L., Fritts, D. C., Williams, B. P., Goldberg, R. A., Schmidlin, F. J., and Blum, U.: Gravity waves in the middle atmosphere during the MaCWAVE winter campaign: Evidence of mountain wave critical level encounters, Ann. Geophys., this issue, 2006.

Williams, B. P., Friits, D. C., She, C. Y., and Goldberg, R. A.: Gravity wave propagation through a large semidiurnal tide and instabilities in the mesosphere and lower thermosphere during the winter 2003 MaCWAVE rocket campaign, Ann. Geophys., this issue, 2006.

Wu, Q. and Killeen, T. L.: Seasonal dependence of mesospheric gravity waves $(<100 \mathrm{~km})$ at Peach Mountain Observatory, Michigan, Geophys. Res. Lett., 23, 2211-2214, 1996. 